\title{
Binocular Impulse Blockade Prevents the Formation of Ocular Dominance Columns in Cat Visual Cortex
}

\author{
Michael P. Stryker and William A. Harris' \\ Department of Physiology, University of California, San Francisco, California 94143-0444
}

Ocular dominance columns in the cat's visual cortex appear to develop out of an initially overlapping projection by a progressive segregation of the geniculocortical afferents serving the 2 eyes (reviewed in LeVay and Stryker, 1979). To determine whether electrical activity in the visual afferent pathway is involved in this normal, developmental rearrangement of synaptic connections, we blocked the discharge of retinal ganglion cells in both eyes by making repeated intravitreal injections of tetrodotoxin (TTX) during the period in which geniculocortical afferent segregation would normally be taking place. Control experiments for the side effects of the injection procedure, the systemic effects of TTX, and the effects of visual deprivation were carried out, and a series of normal animals of appropriate ages was also studied. We then examined the effects of retinal blockade and the various control procedures on the formation of ocular dominance columns using an anatomical assay, the autoradiographic labeling of geniculocortical afferent terminals in layer IV of the visual cortex by the transneuronal transport of tritiated proline injected into 1 eye, and a physiological assay, the ocular dominance of single cortical cells recorded extracelIularly. After retinal 'I'IX blockade, layer IV was labeled uniformly without periodic fluctuation in grain density, and nearly all cortical cells were driven well through both eyes. These assays thus indicated that retinal blockade completely blocked the formation of ocular dominance columns, unlike any of the control procedures, suggesting that the spontaneous maintained discharge of retinal ganglion cells may have an important role in the normal development of binocular connections in the visual cortex.

In the developing visual cortex of monkey (Hubel et al., 1977; LeVay et al., 1980; Rakic, 1976, 1977) and cat (LeVay et al., 1978), ocular dominance columns appear to form by a progressive segregation of geniculocortical afferents serving the left and right eyes. In kittens younger than 2 weeks of age, physiological and several types of anatomical evidence suggest that afferents serving the 2 eyes make intermingled functional connections (LeVay and Stryker, 1979). These connections are strikingly rearranged during the next 4-8 weeks so that, by 6-10 weeks of age, left and right eye afferents are almost completely segregated.

This segregation process may be profoundly affected by visual stimulation in early life. If the normal balance of visual stim-

\footnotetext{
Received Jan. 21, 1985; revised Apr. 2, 1985; accepted Mar. 17, 1986

This work was supported by NIH Grants R01-EY-02874 and K04-EY00213 and by a Basil O'Connor Research Grant from the March of Dimes Birth Defects Foundation. We thank Profs. Max Cynader and Richard Van Sluyters for the material from dark-reared animals from their laboratories. We gratefilly acknowledge the invaluable assistance of Ms. Sheri Strickland in all aspects of this work.

Correspondence should be addressed to Dr. Michael P. Stryker at the above address.

I Present address: Department of Biology, B-022, University of California, San Diego, La Jolla, CA 92093.

Copyright $(\mathcal{C} 1986$ Society for Neuroscience $0270-6474 / 86 / 082117-17 \$ 02.00 / 0$
}

ulation to the 2 eyes is disrupted by rearing animals with the vision of 1 eye occluded during a critical period in early life, the occluded eye loses its effectiveness in driving most cortical cells (Hubel and Wiesel, 1963). Accordingly, its geniculocortical afferents occupy a greatly reduced fraction of layer IV; while the influence and afferent territory of the eye that had remained open is correspondingly expanded (Hubel et al., 1977; LeVay et al., 1980; Shatz and Stryker, 1978). If the 2 eyes are surgically or optically misaligned during early life, or occluded on alternate days, most cortical neurons lose responsiveness through 1 eye or the other (Hubel and Wiesel, 1965; Van Sluyters and Levitt, 1980), and the geniculocortical afferents appear to segregate more nearly completely than is normally the case (Kalil, 1982; Shatz et al., 1977).

Although visual experience may have a profound influence on the outcome of the segregation process, it is not necessary. Geniculocortical afferents segregate to a considerable extent even in the absence of vision. In the monkey, they start to segregate between 3 and 6 weeks before birth (Rakic, 1976, 1977). By the time of birth, a clear but incomplete segregation is evident from physiological and anatomical studies (Hubel et al., 1977) and metabolic measurements (Des Rosiers et al., 1978). Pattern vision, obviously absent in fetal life, must therefore be unnecessary for the initiation of ocular dominance column formation in this species and does not appear to be necessary for its completion (LeVay et al., 1980; Wiesel and Hubel, 1974).

In the cat, segregation of geniculocortical afferents does not begin until after the time of natural eye opening, allowing, in principle, the possibility of a greater role for visual experience. Review of the literature (see Discussion below) and the findings of control experiments in the present report suggest, however, that in this respect the cat is more similar to the monkey than it is different: Ocular dominance columns do develop to a considerable extent in dark-reared and lid-sutured cats.

Even without visual stimuli, the visual centers of the developing brain may not be electrically silent. Indeed, Mastronarde $(1983 \mathrm{a}, \mathrm{b})$ has shown that there is structure to the spontaneous electrical activity of cat retinal ganglion cells; even in diffuse illumination and at low light levels, the discharges of neighboring cells are closely correlated. The effects of abnormal early experience demonstrate that the pattern of activity in the developing CNS can mold certain aspects of neural connectivity. Could it be that spontaneous electrical activity shapes the formation of ocular dominance columns in the absence of visual experience using the same mechanisms that are involved in experience-dependent changes?

The present experiments are a first step in testing this idea: If activity-dependent mechanisms are involved in the segregating of geniculocortical afferents to form ocular dominance columns, then eliminating all activity in the optic nerves should prevent segregation. We find that retinal activity blockade does prevent ocular dominance segregation, consistent with the idea that the same or similar mechanisms may underlie experience- 


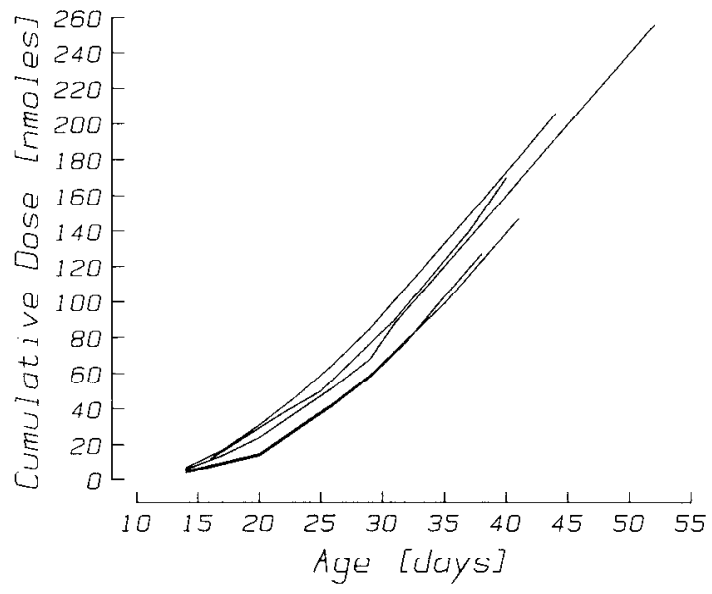

Figure 1. Cumulative dose of TTX to each eye (in nmol; ordinate) as a function of age in days (abscissa) for 5 animals subjected to continuous binocular retinal blockade. Each point indicates the total amount of TTX given to each eye up to the age indicated. The points are connected by straight lines (rather than steps) for the sake of clarity.

independent and -dependent changes in neural connectivity.

Some of the results reported here have appeared in abstract form (Stryker, 1980, 1981).

\section{Materials and Methods}

\section{Animals and rearing}

All kittens, except for the dark-reared group, were bred in a special pathogen-free cat colony in the University of California vivarium. All were normally pigmented. Pregnant cats were inspected every day so that birth dates were known to the nearest day. Throughout the duration of the present experiments, kittens were maintained with their mothers in $1 \mathrm{~m}^{3}$ cages containing a shelf, nest box, and litter box and were given ad libitum access to food and water. Pregnant and nursing cats' diets were supplemented with canned cat food. Kittens 16, 17, 23, 46, and 47 were reared in constant darkness by Prof. M. Cynader in his laboratory at Dalhousie University. Geniculate and cortical tissue from these animals was kindly provided to us for analysis. Kittens 103, 104, and 105 were dark-reared in Prof. R. Van Sluyters' facility at the University of California, Berkeley, and were transported to the USCF laboratory in a light-tight enclosure $1 \mathrm{hr}$ before the terminal physiology experiment.

One of 5 different treatments was applied to kittens between the ages of $14 \mathrm{~d}$ and 6-8 weeks: bilateral retinal blockade by repeated intravitreal injection of tetrodotoxin (TTX); a control for the effects of repeated intravitreal injections using the citrate buffer solution in which the TTX was dissolved; a control for the systemic effects of TTX administration; and 2 controls for the effects of visual deprivation using either binocular lid-suture or dark-rearing. After these treatments, the organization of geniculocortical afferents in area 17 and of the cortical ocular dominance columns was assayed by making microelectrode recordings and/or by quantitative autoradiography following transneuronal transport of ${ }^{3} \mathrm{H}$ proline injected onto 1 eye (LeVay et al., 1978). The treatments and assays accorded each of these animals are summarized in Table 1. For comparison, exactly the same assays were conducted on 3 groups of normal cats: 2-week-olds (12-17 d), 6- to 8-week-olds, and adults.

An initial group of animals was studied following monocular injections of TTX in order to determine appropriate doses and to verify the effectiveness of retinal blockade.

\section{Eye injections}

Lyophilized TTX (1 mg, Calbiochem catalog no. 584411) in citrate buffer $\left(5 \mathrm{mg}\right.$ ) was diluted with $313 \mu \mathrm{l}$ sterile saline to make a $10^{-2} \mathrm{M}$ stock solution, which was stored at $-20^{\circ} \mathrm{C}$. The injection mixture of $5 \times 10^{-3} \mathrm{M}$ TTX was diluted from this stock solution $100 \mu \mathrm{l}$ at a time and was also kept frozen until minutes before use. A $0.0035 \mathrm{M}$ citrate buffer vehicle solution, $\mathrm{pH} 4.8$, used for control injections was similarly stored frozen.

Continuous retinal blockade was produced by repeated injection of
1-10 $\mu \mathrm{l}$ of the injection mixture into the vitreous humor. Dosage was adjusted according to the duration of the blockade produced in each animal (see below). Typically, TTX injections were given every $3 \mathrm{~d}$, with an initial dose of $1 \mu$ lincreased by $5-10 \%$ with each injection. Plots of typical cumulative doses are shown in Figure 1.

Eye injections were made using a Hamilton $10 \mu \mathrm{l}$ syringe equipped with a guide and an $18 \mathrm{~mm} 30$ gauge removable needle. A flange $3 \mathrm{~mm}$ from the tip prevented insertion of the needle too far into the eye. The needle was kept sharp by daily examination under a dissecting microscope and honing when necessary using an Arkansas stone.

Kittens were anesthetized with halothane during surgery. An incision made in the lateral canthus and the conjunctiva exposed the injection site on the lateral margin of the eye just behind the ora serrata. Each injection site was reused as many times as possible. To prevent leakage of the TTX into the choriocapillaris or back out of the eye, the needle was inserted and withdrawn once before each injection of TTX; if bleeding occurred, a new injection site was chosen. After the injection, the needle was held in place for $30 \mathrm{sec}$, and a cotton pledget was used to remove any fluid that escaped. The incision was then closed using a wound clip.

The quantity of TTX injected was greater than a lethal dose if injected systemically. Because it was released from the eye only slowly, it appeared to cause no systemic effects after successful injections.

\section{Control experiments}

In addition to normal animals of various agcs, 4 groups of control animals were studied. One group of 3 animals was designed to control for effects of the eye injection procedure. These animals received repeated intravitreal injections of the same amounts of citrate buffer vehicle solution as were injected with the TTX in the experimental animals.

A second group of 2 animals was designed to control for the systemic effects of TTX. A series of osmotic minipumps (Alza model 2001) filled with TTX solutions of increasing concentration were implanted subcutaneously on days $17,24,31$, and 38 of age to deliver continuously approximately 4 times the cumulative dose of TTX that was injected into the experimental animals. These pumps delivered $1 \mu \mathrm{l} / \mathrm{hr}$ continuously over the time they were implanted; concentrations of TTX were $0.58,0.94,1.14$, and $1.42 \mathrm{~mm}$.

A third group of 11 animals was deprived of pattern vision by bilateral lid suture from either the time of natural eye-opening, about 6-8 d, or the time at which retinal blockade was begun in the TTX-treated experimental group, about $14 \mathrm{~d}$ of age. Under aseptic conditions, eyelids were fused using 4 mattress sutures. Sutures were removed a week later. Animals were inspected daily for gaps in the fused eyelids, and those in which such "windows" were found have been excluded from the present report.

A fourth group of 8 animals was deprived of all visual experience by rearing them in constant darkness from the day of birth or day 4 of age.

\section{Anatomy}

Anatomical assays of the state of segregation of left- from right-eye geniculocortical afferents were made using the transneuronal transport of an isotopically labeled amino acid $\left(\mathrm{L}-\left[3,4(n)-{ }^{3} \mathrm{H}\right]\right.$ proline, $40 \mathrm{Ci} / \mathrm{mmol}$, Amersham catalog no. TRK.439) injected into 1 eye. Techniques used for this procedure were similar to those described in LeVay et al. (1978). Departures from the published procedures are noted at the appropriate places in Results.

The quantity of ${ }^{3} \mathrm{H}$-proline concentrated for injection was always 2 $\mathrm{mCi}$. It was diluted in 10-20 $\mu \mathrm{l}$ sterile saline. Scintillation counting of the residual radioactivity remaining in the syringe and concentrating vial and on the surface of the eyeball after the injection revealed that the actual quantity injected was between 1.2 and $1.95 \mathrm{mCi}$. If more 0.8 $\mathrm{mCi}$ was recovered outside the eye, a second injection was made.

\section{Physiology}

Microelectrode recordings were made in control animals and in 4 kittens that had undergone binocular retinal blockade from $14 \mathrm{~d}$ to $5.5-8.5$ weeks of age. Two to 5 days after the end of the retinal blockade, one or a few horizontal microelectrode penetrations were made through the medial bank of area 17 from Horsley-Clarke posterior 6-9 to anterior 4-6. Visual receptive fields of the single units studied were located within $15^{\circ}$ of the area centralis.

The chief aim of the microelectrode studies was to determine the 
Table 1. Treatments, ages, and anatomical and physiological findings on 5 groups of experimental animals

\begin{tabular}{|c|c|c|c|c|c|c|c|}
\hline Treatment & $\begin{array}{l}\text { Animal } \\
\text { number }\end{array}$ & $\begin{array}{l}\text { Age } \\
\text { begun }\end{array}$ & $\begin{array}{l}\text { Age } \\
\text { ended }\end{array}$ & $\begin{array}{l}\text { Age at } \\
\text { perfusion }\end{array}$ & $\begin{array}{l}\text { Periodic } \\
\text { labeling }\end{array}$ & $\begin{array}{l}\text { Number } \\
\text { of units }\end{array}$ & $\begin{array}{l}\text { Monoc- } \\
\text { ular } \\
\text { index }\end{array}$ \\
\hline \multirow{9}{*}{$\begin{array}{l}\text { Binocular } \\
\text { TTX }\end{array}$} & 7 & 12 & 41 & 42 & 0 & & \\
\hline & 12 & 15 & 37 & 37 & 0 & & \\
\hline & 35 & 14 & 40 & 40 & 0 & & \\
\hline & 36 & 14 & 43 & 43 & 0 & & \\
\hline & 37 & 14 & 57 & 59 & 0 & 25 & 0.12 \\
\hline & 50 & 14 & 45 & 45 & 0 & & \\
\hline & 73 & 16 & 44 & 45 & 0 & 28 & 0.15 \\
\hline & 76 & 14 & 39 & 41 & 0 & 46 & 0.17 \\
\hline & 77 & 14 & 39 & 42 & 0 & 72 & 0.19 \\
\hline \multirow{3}{*}{$\begin{array}{l}\text { Vehicle eye } \\
\text { injections }\end{array}$} & 186 & 12 & 65 & 65 & +++ & 81 & 0.46 \\
\hline & 187 & 14 & 60 & 60 & +++ & 128 & 0.65 \\
\hline & 188 & 14 & 60 & 65 & +++ & & \\
\hline \multirow{2}{*}{$\begin{array}{c}\text { Systemic } \\
\text { TTX }\end{array}$} & 178 & 15 & 46 & 47 & $\mathrm{f}$ & 45 & 0.41 \\
\hline & 179 & 15 & 46 & 54 & f & 57 & 0.47 \\
\hline \multirow[t]{11}{*}{ Lid-sutured } & 2 & 6 & 42 & 42 & ++ & & \\
\hline & 3 & 6 & 42 & 42 & + & & \\
\hline & 14 & 15 & 43 & 43 & + & & \\
\hline & 31 & 10 & 87 & 87 & +++ & & \\
\hline & 32 & 10 & 89 & 89 & f & 11 & 0.64 \\
\hline & 38 & 14 & 40 & 40 & ++ & 63 & 0.52 \\
\hline & 42 & 6 & 43 & 43 & ++ & & \\
\hline & 44 & 6 & 43 & 43 & ++ & 48 & 0.58 \\
\hline & 97 & 17 & 86 & 86 & $\mathrm{c}++$, if & & \\
\hline & 254 & 7 & 211 & 211 & f & 27 & 0.54 \\
\hline & 261 & 14 & 243 & 243 & - & 38 & 0.42 \\
\hline \multirow[t]{8}{*}{ Dark-reared } & 16 & 1 & 92 & 92 & + & & \\
\hline & 17 & 1 & 92 & 92 & ++ & & \\
\hline & 23 & 1 & 122 & 122 & + & & \\
\hline & 46 & 1 & 63 & 63 & ++ & & \\
\hline & 47 & 1 & 63 & 63 & ++ & & \\
\hline & 103 & 4 & 43 & 43 & $\mathrm{c}++$, if & 69 & 0.51 \\
\hline & 104 & 4 & 48 & 48 & $c+$, if & 52 & 0.60 \\
\hline & 105 & 4 & 41 & 41 & $\mathrm{f}$ & & \\
\hline
\end{tabular}

Columns 1 and 2 are self-explanatory. Columns 3 and 4 show the age in days that the indicated treatment was begun and ended for each animal. Column 5 shows the age in days at perfusion. The appearance of transneuronal autoradiographic labeling in the visual cortex is indicated in column $6: 0$, labeling was continuous with no indication of periodic variation along layer $4 ;+$, periodicity could faintly be discerned; ++ , clearly periodic labeling but with apparent continuity between the densely labeled patches; +++ , clearly periodic labeling with apparent gaps (of ncar-background labcling) between the densely labeled patches; - , transneuronal labeling was not performed; $f$, although isotope was injected into the eye, the transneuronal labeling procedure failed, producing no results; $c$ and $i$, contralateral and ipsilateral hemispheres with respect to the injected eye when findings for the 2 were different. Columns 7 and 8 present the results from visual cortex recordings in each animal in which recordings were made. Column 7 shows the number of visually responsive single units studied. Column 8 shows the monocularity index, calculated as described in Materials and Methods; values of this index are nearer 0 to the extent that neurons are driven equally well by the 2 eyes and nearer 1 to the extent that each neuron is dominated or driven exclusively by one eye or the other.

relative contributions from the 2 eyes to the discharge of neurons in area 17 , with special attention to layer IV, within which the geniculocortical afferents principally terminate. After moving the electrode 80 $100 \mu \mathrm{m}$ from the previous single unit studied, the preferred orientation of the multiunit background activity was determined through the eye that drove it more strongly. Using this orientation as a starting point, the preferred orientation of a single unit isolated by the microelectrode was then determined through both eyes. The relative strength of the monocular responses evoked through the 2 eyes was finally used to categorize the ocular dominance of each single unit on a 7-point scale following Hubel and Wiesel (1962).

A monocularity index was used to represent with a single number the degree of binocularity among a sample of cortical neurons. This index was calculated as follows:

$$
\frac{(1+7)+[2 / 3 \times(2+6)]+[1 / 3 \times(3+5)]}{(1+2+3+4+5+6+7)}
$$

where italicized numbers represent the number of neurons in each ocular dominance category. If all neurons in a sample were monocularly driven, which is to say within ocular dominance groups 1 and 7 , this index would take a value of 1 . The value of the index would be 0 for a sample of neurons all of which fell into ocular dominance group 4, and it would be intermediate between these 2 values for intermediate degrees of 
Figure 2. Visual evoked potentials recorded from the scalp of cat 331 at $102 \mathrm{hr}$ following TTX injection into the right eye. Left, Responses to stroboscopic stimulation of left eye; right, lack of response to stimulation of right eye. In both panels, responses recorded from left posterior scalp electrode are shown above; those from right posterior scalp electrode are shown below. Tick marks on ordinate, 100 $\mu \mathrm{V} ;$ tick marks on abscissa, $100 \mathrm{msec}$. Stimulus was presented at $100 \mathrm{msec}$ (first tick mark).
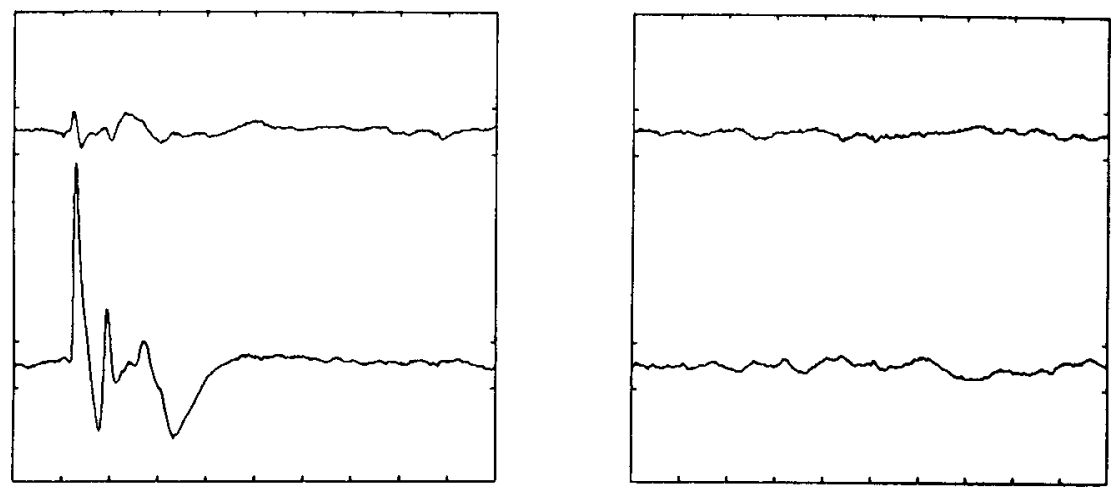

binocular segregation. This index, based on an ordinal scalc of ocular dominance, is not truly quantitative, but it has the virtue of being influenced to an equal extent by a one-category error in the assignment of a unit to any ocular dominance class.

\section{Results}

\section{Monocular TTX injections}

Three adult cats and 4 kittens were studied after injections of TTX into only 1 eye in order to determine appropriate doses and to verify the effectiveness of the retinal blockade so produced.

Results from cat 331 (age 6 months, weight $3.3 \mathrm{~kg}$ ) were typical of these experiments and will be described. Twelve hours after the injection of $8.4 \mu \mathrm{l} 5 \times 10^{-3} \mathrm{M}$ TTX into the right eye, the right pupil was tonically fully dilated, and no direct or consensual pupillary response could be obtained in that eye. A direct response but no consensual response was present in the intact left eye. This situation persisted for $60 \mathrm{hr}$ from the time of injection, when the tonic dilatation of the pupil began to decrease slightly. A very slight consensual pupillary response then appeared in the right eye, without any direct response in the right eye or consensual response in the left eye. By $72 \mathrm{hr}$ after the TTX injection, the tonic dilatation of the right eye was still less, and its consensual pupillary response was somewhat stronger. By $84 \mathrm{hr}$ after the TTX injection, the tonic state of the 2 pupils was similar while handling the cat in mesopic illumination, and the right eye's consensual response appeared equal to the direct response obtained by illuminating the left eye. There was still, however, no direct or consensual pupillary response to illumination of the right eye.

At this time, the animal was prepared for visual cortical evoked potential recordings and microelectrode single-unit recordings in the right dorsal lateral geniculate nucleus (LGN). No cortical evoked potential $(<10 \mu \mathrm{V})$ was obtained from right eye stimulation, while a large and reliable evoked potential $(>400 \mu \mathrm{V})$ was elicited by a stimulus flash to the left. Between 88 and 100 hr after the TTX injection, single units in laminae $A$ and $C$ of the right LGN were found to have normal visual receptive fields driven from the left eye, while units in lamina $A 1$ were silent or had extremely low spontaneous activity, and were unresponsive to stimulation of either eye. Some of the units in lamina Al had their abnormally low rates of spontaneous activity further depressed by stimulation of the left eye. The left half of Figure 2 illustrates the potentials evoked from the scalp over the left posterior cortex (top) and right posterior cortex (bottom) by stroboscopic stimulation of the unblocked left eye $102 \mathrm{hr}$ after the TTX injection. The very much larger contralateral response was commonly found in such recordings. The right half of the figure makes evident the lack of such evoked potentials to visual stimulation through the blocked right eye at this time.

At $110 \mathrm{hr}$ after TTX injection, a visual evoked potential to right eye stimulation was first obtained. Right and left eye responses recorded from supradural electrodes over the visual cortices at $112 \mathrm{hr}$ following the TTX injection are shown in Figure 3. Note that within a few hours after a visual evoked potential was first visible, it was of nearly normal size. Frequently the cortical evoked potentials from such an eye were even larger than those from the intact eye in the early stages of recovery from TTX blockade. At this time as well, single units in geniculate lamina $A 1$ were found to be driven from the right eye. The initial responses found were characteristically more transient than a sample from an electrode penetration into the lateral geniculate nucleus of an intact animal, but a quantitative study of this possible abnormality was not attempted. Most striking was the apparent normality of the newly responsive geniculate receptive fields: All had center-surround organization with receptive field sizes that were within a factor of 2 of those of the lamina-A neurons encountered in the same electrode penetration.

We interpret these findings as follows: During the first 60-72 hr after TTX injection, the pupillomotor innervation was blocked, leaving the pupil in tonic dilatation. By $84 \mathrm{hr}$, the
Figure 3. Visual evoked potentials recorded through supradural electrodes over the areae centrales representions (Horsley-Clarke coordinates AP -2 , Lat 2.5) of the 2 hemispheres of cat 331 at $112 \mathrm{hr}$ following TTX injection into right eye. Display conventions as in Figure 2.
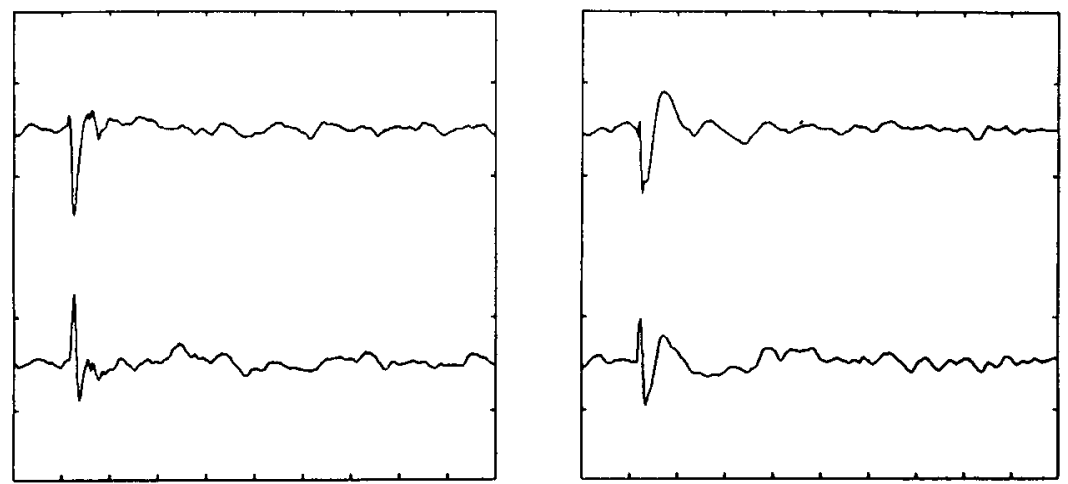

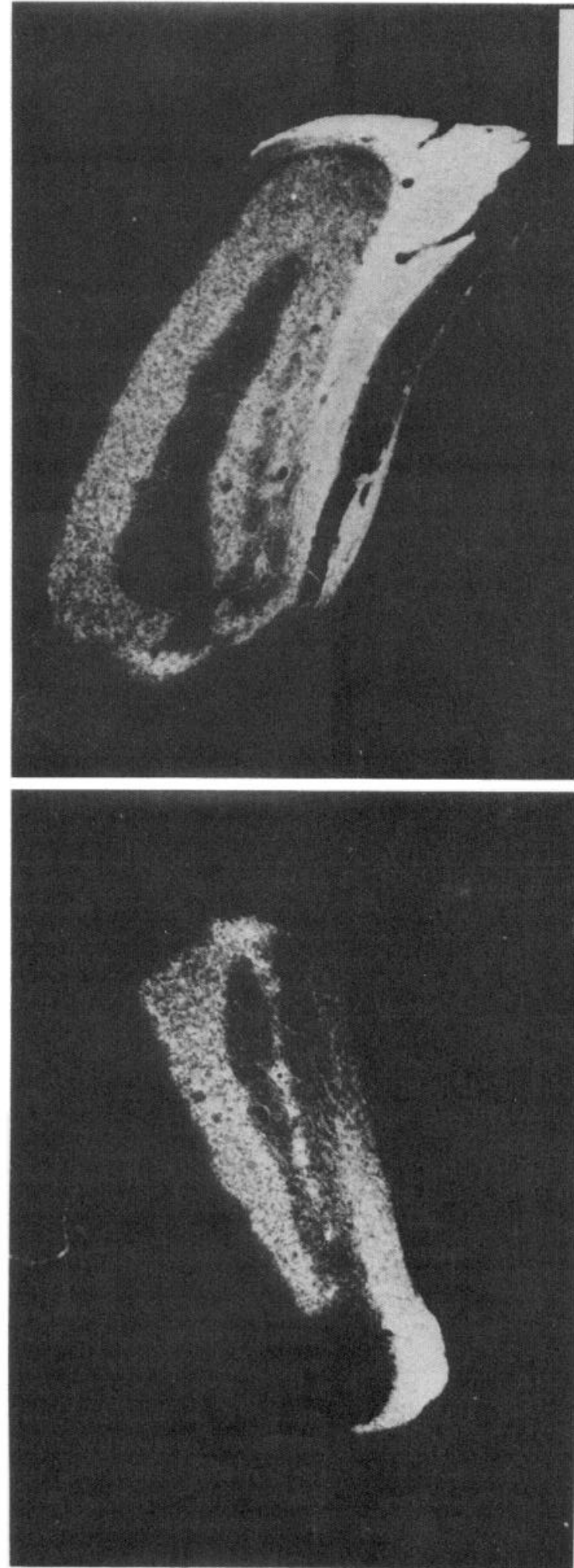

3 :

혈을

흥형

高

융

要

䒿它

宽

을

뭉

巴ल

놈

.

동

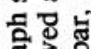

원

药

灵是

$\checkmark$ 品

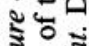

象药 


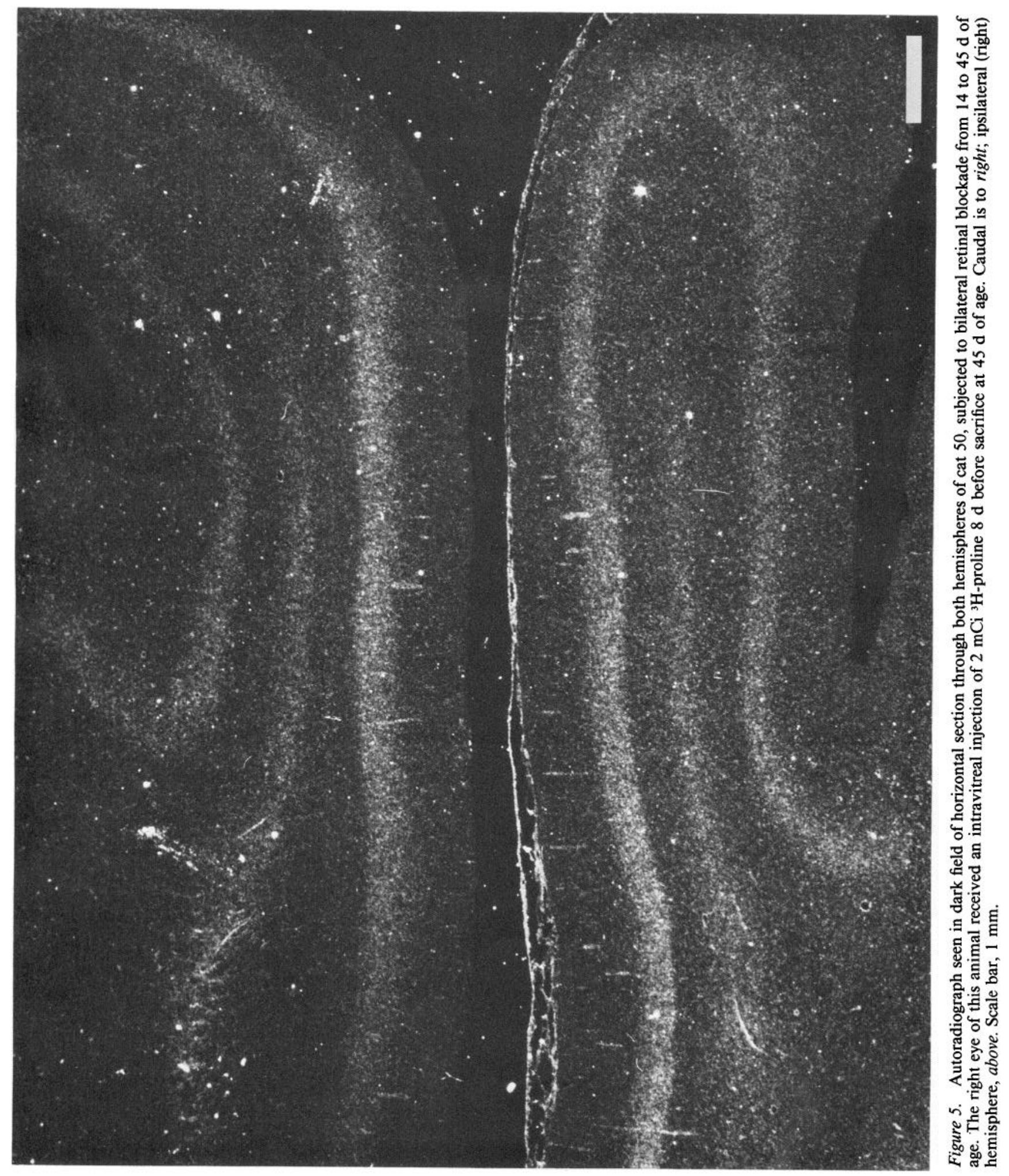


pupillomotor blockade had lifted completely. The blockade of retinal ganglion cell axons, however, remained complete for an additional $24 \mathrm{hr}$, until $110 \mathrm{hr}$ after the TTX injection, during the second day of the microelectrode recording experiment.

This sequence of events was invariably followed in all such animals tested: First, a period of complete pupillomotor blockade lasting from 2-3 d, decreasing over an additional half to full day. Retinal blockade then continued for an additional 1$2 \mathrm{~d}$ after the pupillomotor blockade had subsided. In the youngest animals studied, at 2 weeks of age, the times tended to be at the shorter end of the range, while by 6 weeks the timing was usually similar to that in cat 331 described above. Daily, and usually twice-daily, observation of the state of the pupils thus gave us at least a day's notice of impending offset of retinal blockade, allowing us to inject another loading dose of TTX in order to maintain retinal blockade continuously.

\section{Binocular TTX injections}

The sequence of events following binocular TTX injections was monitored by observation of the pupils and visual cortical evoked potential recording and was found to be similar to the monocular case in the duration of the pupillomotor blockade and the period between its offset and that of the retinal blockade. Microelectrode recordings in the lateral geniculate nucleus during binocular retinal blockade were not systematically attempted.

Nine kittens were maintained under continuous bilateral retinal blockade by binocular TTX injections at approximate $3 \mathrm{~d}$ intervals beginning at about $14 \mathrm{~d}$ of age and ending at 6-8 weeks of age. The starting age was chosen because the geniculocortical axons have not yet begun to segregate from each other according to eye preference at this time (LeVay et al., 1978). The final age was chosen because the eye injection procedure became more difficult as the animal grew larger, and 5-6 weeks of age was the earliest time at which the anatomical and physiological assays used in earlier studies revealed clear segregation of afferents on both sides of the brain of normal animals.

\section{Anatomical findings}

Five kittens received intravitreal injections of $2 \mathrm{mCi}{ }^{3} \mathrm{H}$-proline approximately $4 \mathrm{~d}$ before the final TTX injection and were killed and perfused 7 days later, while both retinae remained blocked. Autoradiography of the $\mathrm{LGN}$ revealed that laminae $\mathrm{A}$ and $\mathrm{C}$ contralateral to the eye injected with label were filled with transportcd radioactivity. Laminae $\mathrm{Al}$ and $\mathrm{Cl}$ were labeled on the ipsilateral side. The entirely normal appearance of geniculate labeling is illustrated in Figure 4, which shows a representative coronal section.

In horizontal sections through the visual cortex, layer IV was labeled continuously on both sides, without any pcriodic waxing and waning of grain density. Such a pattern of labeling, illustrated in Figure 5, would be normal for an animal 2 weeks of age, the time at which the retinal activity blockade was initiated, but it is clearly abnormal for an animal 6 weeks old (LeVay et al., 1978).

The appearance of the cortical labeling was consistent with the possibility that the geniculocortical afferents had failed to segregate as they would have in normal development and had continued to terminate in the immature, overlapping pattern. Before accepting this conclusion, however, it is necessary to deal with an artifact of the transneuronal labeling method that could account for continuous labeling even in the presence of segregated terminal fields (LeVay et al., 1978). This artifact, termed "spillover," results from the labeling of geniculate cells serving both eyes following an injection of tracer into only 1 eye. In normal animals younger than 4 weeks of age, this artifact is very large, especially in the hemisphere contralateral to the labeled eye. By the age of 6 weeks, this artifact, while quantitatively significant, no longer obscures the appearance of segregated ocu- lar dominance patches in normal animals. If spillover in TTX animals were much greater than normal, then the appearance of continuous labeling of layer IV could not be taken to indicate that the geniculocortical afferents had failed to segregate.

To take account of this artifact, LeVay et al. (1978) devised a procedure based on the hypothesis that the relative labeling of geniculate terminals in the cortex is proportional to the relative labeling of other compartments of the geniculate cells. By measuring the labeling of the nuclei of geniculate cells in laminae $A$ and $A l$, it is possible to predict the maximum and minimum cortical grain densities that would result from completely segregated terminals in the region of cortex corresponding to the geniculate region measured. The extent of segregation may be measured by the degree to which the measured cortical grain density fluctuations approach the theoretical maximum and minimum values. Evidence that this procedure provides a satisfactory correction for the "spillover" artifact is presented in LeVay et al. (1978).

Cortical and geniculate autoradiographic sections from 3 binocular TTX animals were studied quantitatively using this procedure. Spillover was found to be $23 \%$ (range $19-30 \%$ ) on the ipsilateral side and $49 \%$ (range $43-60 \%$ ) on the contralateral side, values similar to those in normal animals of the same age. The flat cortical grain distributions (see Fig. 18 below) were far from the theoretical maximum and minimum values set by geniculate spillover. We conclude that the anatomical findings provide strong evidence that binocular retinal blockade prevents the segregation of geniculocortical afferents.

In another 4 kittens, the retinal blockade was terminated 2$7 \mathrm{~d}$ before killing the animal by omitting the final 1 or 2 TTX injection(s) from the procedure described above. These animals were studied both anatomically, using the transneuronal transport method, and physiologically, as described in the next section. Anatomical findings on these animals were indistinguishable from those on the animals that had had their retinal blockade maintained until the time of perfusion.

\section{Physiological findings}

Microelectrode recordings were made in 4 kittens that had undergone binocular retinal blockade from $14 \mathrm{~d}$ to 5.5-8.5 weeks of age. Some of these animals were also studied autoradiographically, as described above, after injection of 1 eye with ${ }^{3} \mathrm{H}$ proline; physiological findings on these were indistinguishable from those in animals not subjected to proline injections.

Two to 5 days after the end of the retinal blockade, one or a few long horizontal microelectrode penetrations were made through the medial bank of area 17 from Horsley-Clarke posterior 6-9 to anterior 4-6. Visual receptive fields of the single units encountered progressed from the upper to lower fields, and all were located within $15^{\circ}$ of the area centralis.

The visual responses of the 192 single units encountered were surprisingly vigorous compared to dark-reared and lid-sutured animals of a similar age. It is to be noted, however, that in contrast to the binocularly deprived animals usually studied, these TTX-treated animals had had comparatively normal visual experience for 1-2 d immediately preceding acute recording. About half $(65 \%)$ of the neurons were "selective" $(36 \%)$ or "biased" (29\%) for stimulus orientation (terms defined in Blakemore and Van Sluyters, 1975), 20\% werc vigorously responsive but with nonoriented or diffuse receptive fields, only $8 \%$ poorly responsive, and even fewer (7\%) were visually unresponsive.

The ocular dominance of single cortical neurons was the main subject of interest. Figure 6 shows the pooled ocular dominance histogram from these 4 animals. Data illustrated in Figures 10 and 19 below illustrate the consistency of findings among the individual animals of this group. Nearly all $(91 \%)$ of the cortical neurons encountered were driven similarly by the 2 eyes, falling into the middle (3-5) ocular dominance groups. Even within 


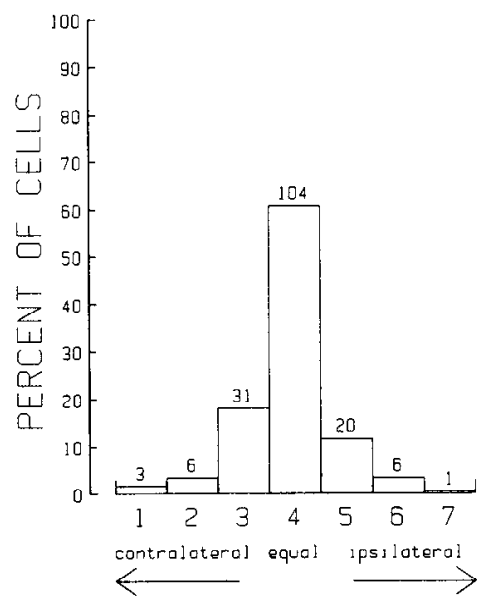

Figure 6. Ocular dominance histogram compiled from 171 visually responsive cortical single units in cats $37,73,76$, and 77 , subjected to bilateral retinal blockade from days 14-16 until days 39-57 and allowed to recover from blockade for $2-4 \mathrm{~d}$ before microelectrode recording. Histogram plots percentage of units in each of 7 ocular dominance groups defined by Hubel and Wiesel (1962): group 1 (7) for units driven exclusively through contralateral (ipsilateral) eye; group 2 (6) for units strongly dominated by contralateral (ipsilateral) eye; group 3 (5) for units weakly dominated by contralateral (ipsilateral) eye; and group 4 for units driven nearly equally through the 2 eyes. Number of units in each bar of histogram is indicated above bar.

this restricted range of eye-dominance groups, no systematic variation of an appropriate period was evident. An overall bias in favor of the contralateral eye, while present in these animals ( 40 contralaterally dominated units compared to 27 ipsilaterally dominated units), was less pronounced than in normal and control animals (see below).

No abnormalities were noted in 6 vertical microelectrode penetrations made into the lateral geniculate nucleus in 2 of these animals. Except at the borders between laminae, multiunit activity was driven exclusively from one eye or the other, and all of the 47 single units studied were monocularly driven.

\section{Normal development}

To supplement data available from the literature and from our own earlier work, anatomical and physiological studies were

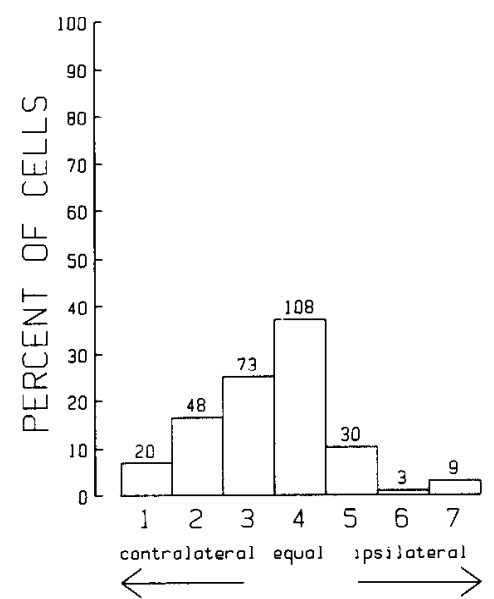

Figure 7. Ocular dominance histogram compiled from 291 visually responsive cortical single units in the central $25^{\circ}$ of the visual field in 4 normal cats $12,13,13$, and $17 \mathrm{~d}$ of age, the approximate ages at which TTX blockade was initiated in the experimental group. Data shown from the 3 oldest cats of this group are from LeVay et al. (1978). Conventions as in Figure 6.

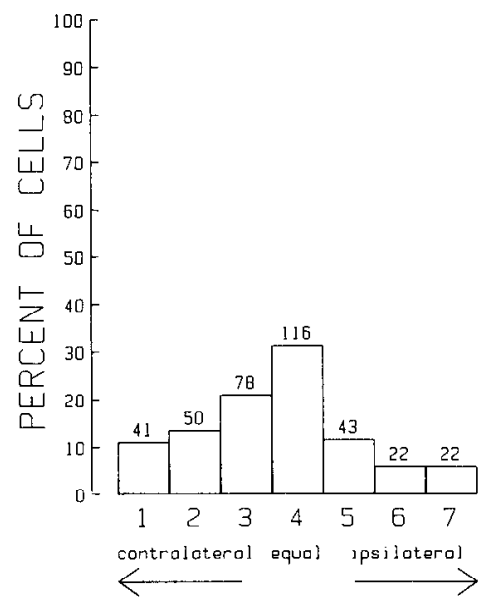

Figure 8. Ocular dominance histogram compiled from 372 visually responsive cortical single units in 6 normal cats $36,37,39,45,45$, and $51 \mathrm{~d}$ of age. These recordings were made at an average age similar to that of the experimental group subjected to TTX blockade. Conventions as in Figure 6.

conducted on 3 groups of normal cats of different ages: 2 weeks old, 5-8 weeks old, and adult. Representative transneuronal autoradiographic sections from such animals are illustrated in LeVay et al. (1978). Figure 7 illustrates the pooled ocular dominance histogram from 291 single units recorded in 4 normal 2 -week-old kittens. Only $10 \%$ of these neurons were monocularly driven.

Figure 8 shows similar data from 372 units in 6 normal kittens 5-8 weeks of age. By this age, $17 \%$ of the units were monocularly driven. Figure 9 shows ocular dominance data, derived using exactly the same techniques, from 496 single units in 8 normal adult cats. In adult animals, $29 \%$ of the neurons recorded using these techniques were found to be monocularly driven. It is noteworthy that the 5-8 week animals have a considerably smaller proportion of monocular neurons in layer IV and within the visual cortex as a whole than do adults. In both these groups, however, fluctuations in ocular dominance of periods between 300 and $1000 \mu \mathrm{m}$ were evident along the course of the long horizontal microelectrode penetrations. These findings are in accord with the inference made from the transneuronal auto-

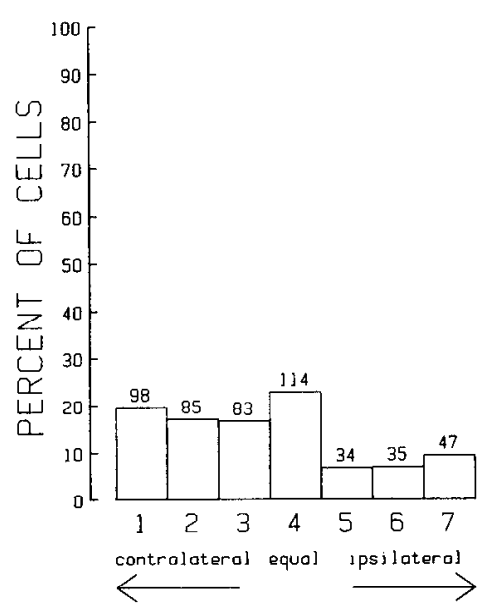

Figure 9. Ocular dominance histogram compiled from 496 visually responsive cortical single units in 8 normal adult cats. Data from the 3 normal animals of Shatz and Stryker (1978) are included in this sample. Conventions as in Figure 6. 

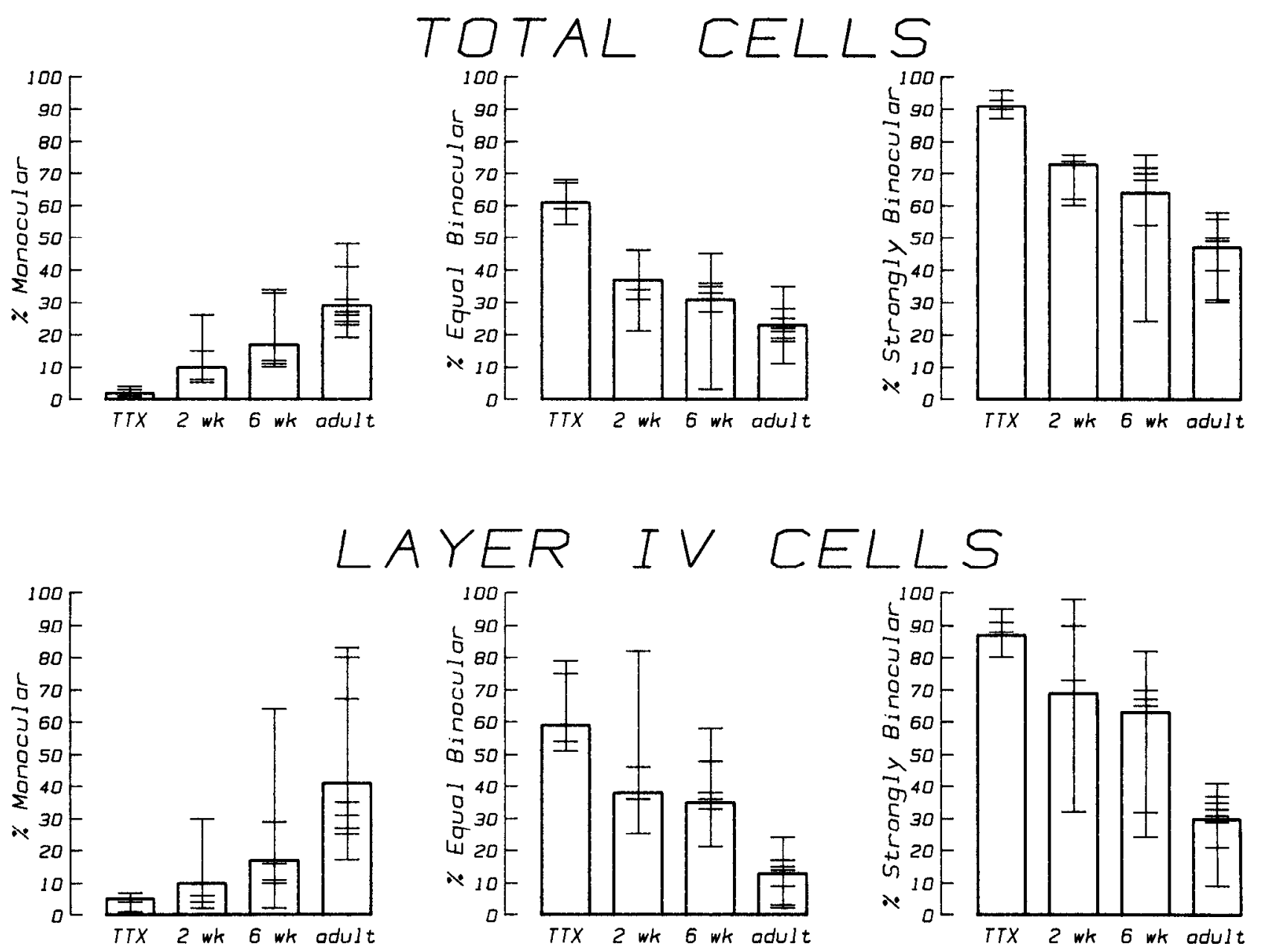

Figure 10. Comparison of ocular dominance findings for all cells and for layer IV cells in the 4 TTX animals subjected to retinal blockade beginning about 2 weeks and studied at about 6-8 weeks of age with those in normal animals about 2 weeks of age, about 5-8 weeks of age, and at adulthood. Ordinates plot the percentage of cells classified as strongly binocular (ocular dominance groups 3-5), equal binocular (ocular dominance group 4), and monocular (ocular dominance groups 1 and 7). Abscissa shows the different groups of animals. The histogram bars represent the pooled data from each group; data from each individual animal are shown as a horizontal line. Vertical error bars span the range of data from the individual animals in each group. Note that for both the entire sample and for the layer IV cells separately, the percentage of monocular cells increases as a function of age, and the percentage of strongly and weakly binocular cells declines as a function of age. Note also that the TTX group is even less monocular and more binocular than the 2 wk group.

radiographic sections, and previous quantitative analysis of these sections (LeVay et al., 1978), that segregation of the afferents serving the 2 eyes has not quite attained adult levels of completeness by $6-8$ weeks.

A comparison of the ocular dominance findings in the binocular TTX-treated animals with those observed in normal development is presented in Figure 10. Figure 10 shows the findings in layer IV separately from those in the other cortical layers. This figure also displays the range of variability among the individual animals studied. It should be noted that the physiological as well as the anatomical ocular dominance findings in TTX-treated animals are most similar to those in normal animals at the age at which the retinal blockade was initiated.

\section{Vehicle solution injections}

Three kittens were treated with binocular injections of the citrate buffer vehicle solution in which the TTX was suspended, using a dose schedule identical to that of TTX-treated kittens. Transneuronal autoradiographic labeling of geniculocortical afferents was performed in all 3 kittens. A representative horizontal section from both hemispheres of 1 of these animals is shown in
Figure 11. It is indistinguishable from such a section from a normal kitten of the same age.

Microelectrode recordings were made from 2 of these animals. The pooled ocular dominance distribution illustrated in Figure 12 is within the normal range, although it is somewhat less binocular than normal. This possible reduction in binocularity may be due in part to imperfect eye alignment produced by the repeated eye injections. The fact that the majority of cells remained binocular suggests that the eyes were at most only slightly or transiently misaligned. The periodic fluctuations in ocular dominance along the course of microelectrode penetrations were more pronounced than normal.

\section{Systemic TTX infusions}

As a control for possible systemic effects of chronic TTX administration, 2 kittens were treated with systemic infusions of approximately 4 times the cumulative dose of TTX that was injected intraocularly in the experimental animals. Throughout the period of treatment, these animals appeared normal in every respect. We observed no behavioral indication that they were receiving any drug. 


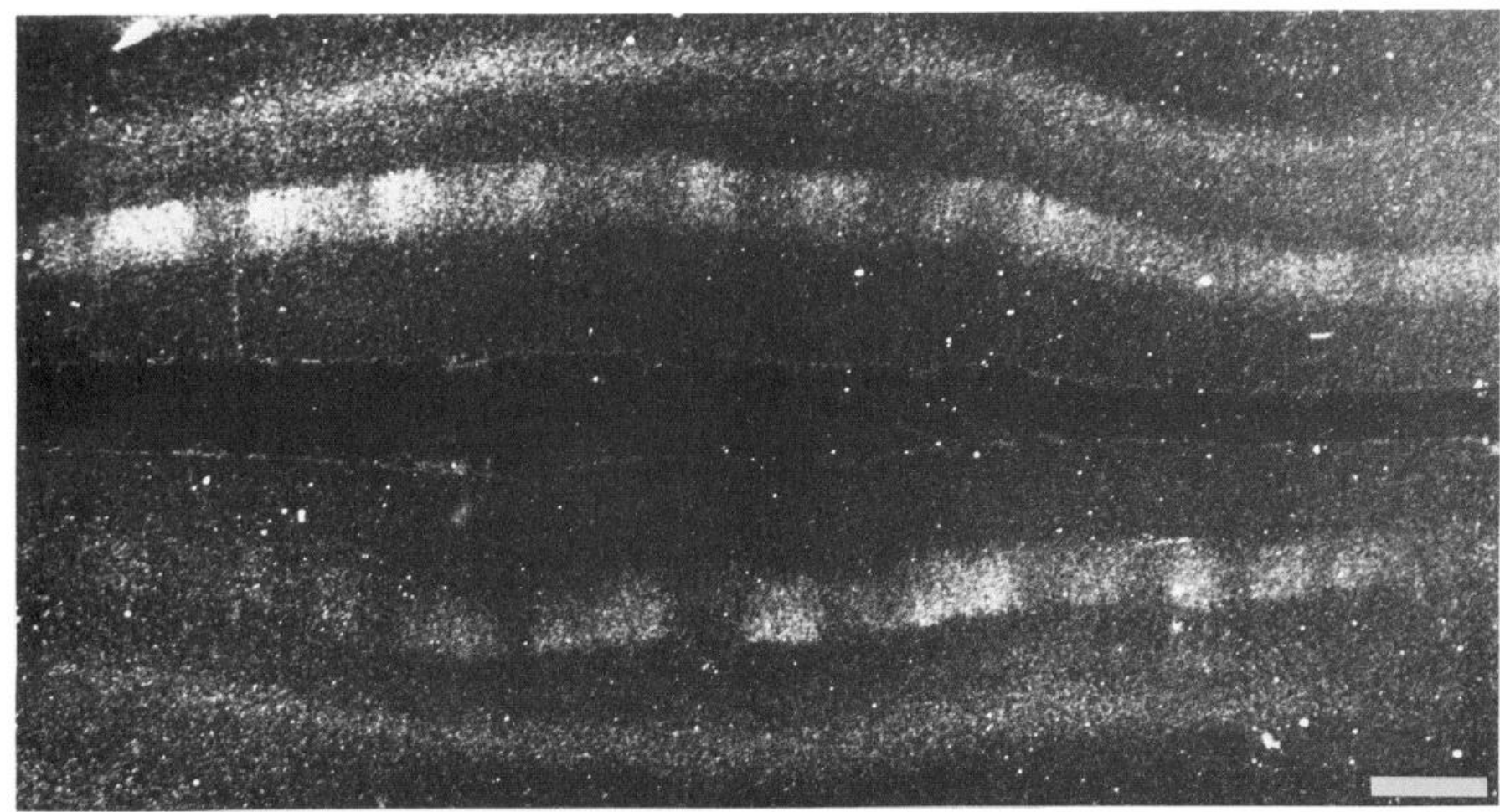

Figure 11. Autoradiograph seen in dark field of horizontal section through both hemispheres in cat 187, subjected to repeated intravitreal injections of the same vehicle solution in which TTX was suspended in the experimental group. The right eye of this animal received an intravitreal injection of $2 \mathrm{mCi}^{3} \mathrm{H}$-proline 9 days before sacrifice at $60 \mathrm{~d}$ of age. Contralateral (left) hemisphere shown above. Other conventions as in Figure 5.

Each of these animals was studied both anatomically, using transneuronal autoradiographic labeling of the geniculocortical afferents, and physiologically, using microelectrode recording. The anatomical studies were unsuccessful in both cases because of artifactually high background labeling. The physiological ocular dominance findings (Fig. 13) were within the normal range, all receptive-field properties appeared to be normal in every respect.

\section{Binocular deprivation by lid suture}

Transneuronal autoradiographic labeling was carried out in 12 cats deprived of vision by bilateral lid suture from prior to the

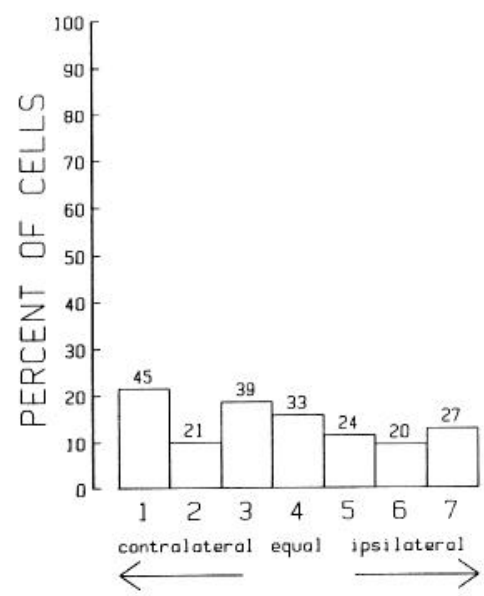

Figure 12. Ocular dominance histogram compiled from 209 visually responsive cortical single units in control cats 186 and 187 , subjected to repeated intravitreal injections of the same vehicle solution in which TTX was suspended in the experimental group. Conventions as in Figure 6. time of natural eye-opening to between 6 weeks to 9 months. Figure 14 shows a representative section for comparison with the TTX results, taken from an animal 7 weeks old. A periodic waxing and waning of label density, consistent with the segregation of geniculocortical afferents serving the 2 eyes, is evident in this section, as it was in all normal and deprived animals 6 weeks of age or older.

Spillover calculations and measurements of the labeling fluctuation were carried out in 3 cases as described above for the TTX-treated animals. Spillover was found to average 23\% (range $22-25 \%$ ) on the ipsilateral side and $40 \%$ (range $36-44 \%$ ) on the contralateral side, values similar to those in normal or TTX-

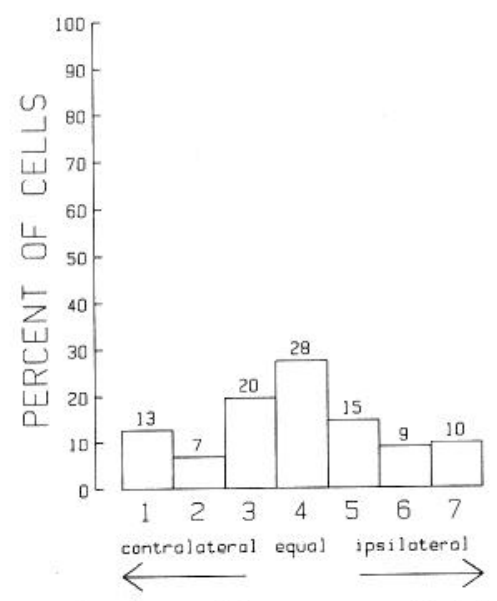

Figure 13. Ocular dominance histogram compiled from 102 visually responsive cortical single units in cats 178 and 179 , subjected to systemic infusion of approximately 4 times the dose of TTX received by the experimental group. Conventions as in Figure 6. 


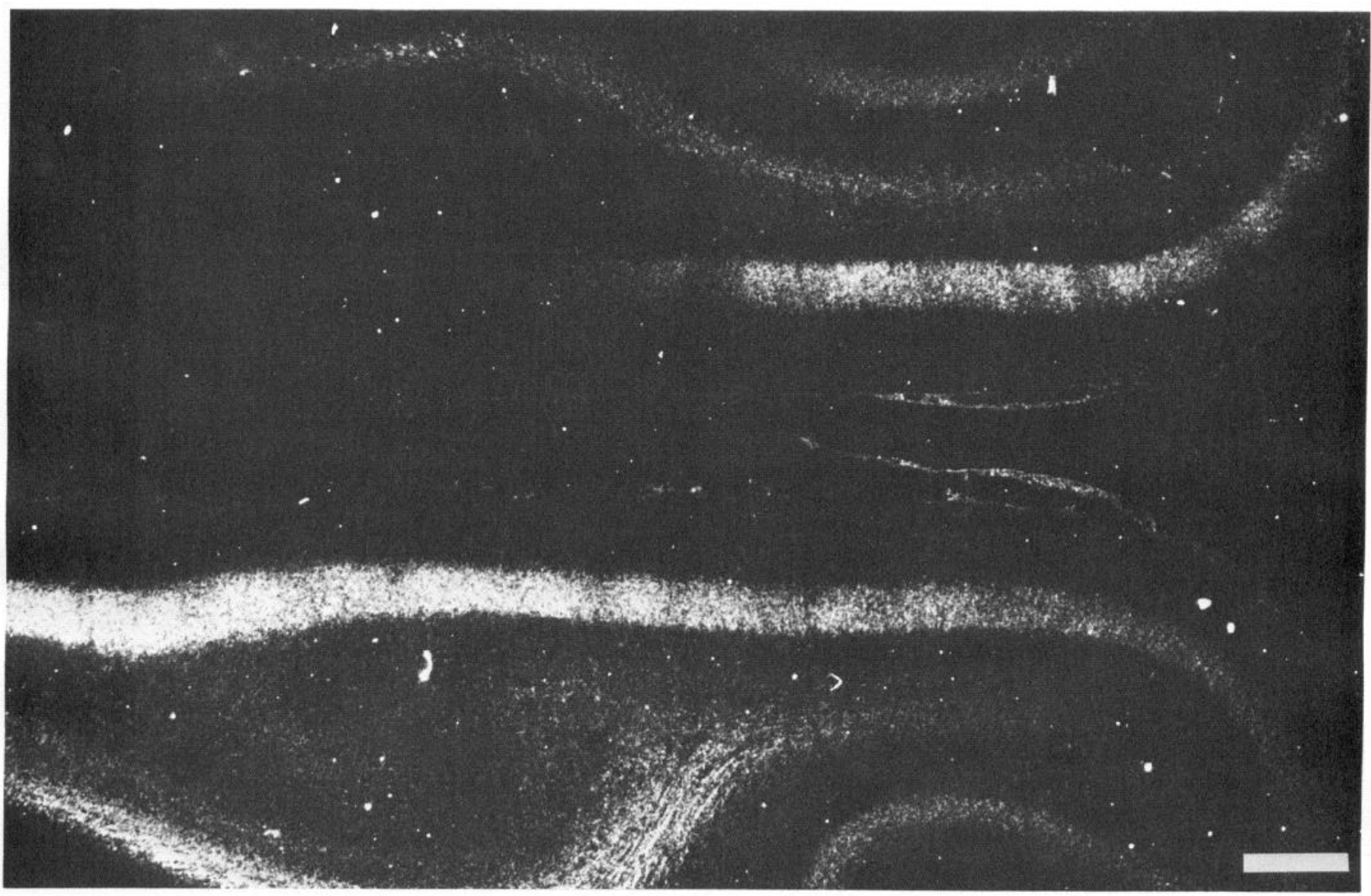

Figure 14. Autoradiograph seen in dark field of horizontal section through both hemispheres in cat 44 , subjected to visual deprivation by bilateral lid suture. The right eye of this animal received an intravitreal injection of $1.2 \mathrm{mCi}{ }^{3} \mathrm{H}$-proline $9 \mathrm{~d}$ and a second injection of $1.0 \mathrm{mCi} 6 \mathrm{~d}$ before the terminal experiment at $43 \mathrm{~d}$ of age. Conventions as in Figure 5.

treated animals. Figure 18 below compares the quantitative anatomical findings in lid-sutured animals with those from some of the other groups.

Ocular dominance was examined physiologically in 5 animals. The pooled ocular dominance histogram shown in Figure 15 shows that these findings as well were within the normal range, although responses to visual stimuli were frequently sluggish or otherwise abnormal.

\section{Binocular deprivation by dark-rearing}

Four dark-reared animals were studied anatomically and 2 physiologically. Findings from these animals were basically similar to those in animals deprived by lid suture. Spillover of transneuronal labeling within the LGN of these animals was greater, however, being about $50 \%$ over the rather similar values found in the lid-sutured, TTX-treated, or normal animals. In 3 darkreared animals, the average values of spillover were $35 \%$ (range $32-38 \%$ ) on the ipsilateral side and $61 \%$ (range $58-63 \%$ ) on the contralateral side. The transneuronally labeled section of cortex shown in Figure 16 shows the characteristic fluctuation in grain density, and the ocular dominance histogram appearing in Figure 17 shows a normal fraction of monocularly driven neurons. The period of fluctuation in ocular dominance evident along the course of microelectrode penetrations in these animals was normal.

\section{Comparison of anatomical findings on visually deprived animals}

Figure 18 shows grain counts made along the base of layer IV in transneuronally labeled autoradiographic sections from nor- mal, TTX-treated, lid-sutured, and dark-reared animals. All other control animals were indistinguishable from normal. The fluctuation of labeling up to or near the limits set by spillover in the lateral geniculate nucleus is evident in all except the TTX data. No region could be found on the TTX sections to contain significant periodic fluctuations in labeling. The anatomical findings in the TTX-treated animals were similar to those in normal 2-week-old animals but were out of the range of variability found in all other groups.

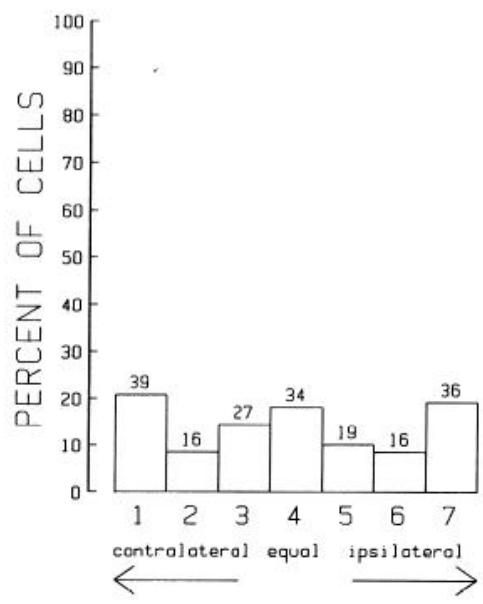

Figure 15. Ocular dominance histogram compiled from 187 visually responsive cortical single units in cats $32,38,44,254$, and 261 , subjected to visual deprivation by bilateral lid suture. Conventions as in Figure 6 . 


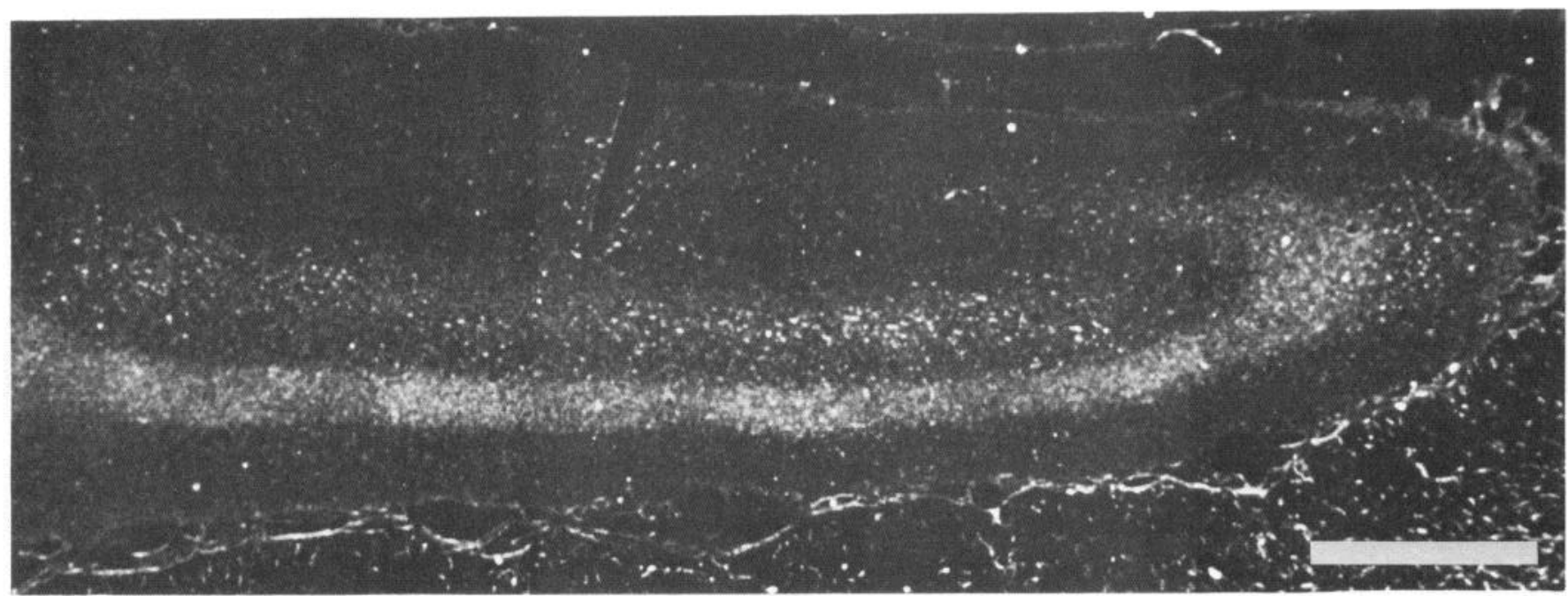

Figure 16. Autoradiograph seen in dark field of horizontal section through the hemisphere ipsilateral to the injected eye in cat 17 , subjected to visual deprivation by dark-rearing. The right eye of this animal received an intravitreal injection of $2 \mathrm{mCi}{ }^{3} \mathrm{H}$-proline $14 \mathrm{~d}$ before perfusion at 92 $\mathrm{d}$ of age. Conventions as in Figure 5.

\section{Comparison of physiological findings}

Figure 19 compares the physiological data on binocularity of cortical neurons in TTX-treated animals with those in all the groups of control animals. Each horizontal line on this figure indicates the monocularity index (see Materials and Methods) for a single animal, with the monocularity indices for the pooled data from each group indicated by the open bars. The error bars show the entire range of data from each group.

All control groups were essentially normal or slightly more monocular than normal. The TTX group was dramatically more binocular than any other group. All data from TTX-treated animals lie out of the range of variation of any other group. In addition, in all groups except for the normal 2-week-old and TTX-treated animals, the horizontal microelectrode penetrations exhibited clear periodic fluctuations in ocular dominance. The periods of these fluctuations were appropriate for ocular dominance columns.

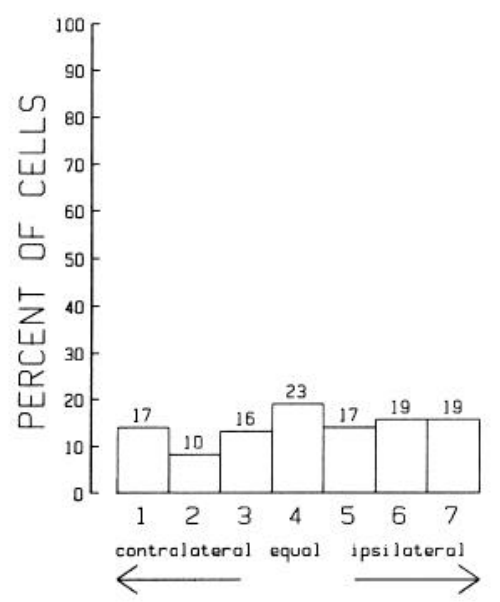

Figure 17. Ocular dominance histogram compiled from 121 visually responsive cortical single units in cats 103 and 104 , subjected to visual deprivation by rearing in continuous darkness. Conventions as in Figure 6.

\section{Discussion}

\section{Interpretation and significance of the present findings}

The present results show that binocular impulse blockade can prevent the normal segregation of geniculocortical afferents serving the 2 eyes within layer IV of the visual cortex and the accompanying formation of physiological ocular dominance columns that span all the cortical layers. In normal development, such binocular segregation is progressive, beginning some time after 2 weeks of age and continuing past 6 weeks (LeVay and Stryker, 1979).

Because retinal blockade was maintained in these experiments only until 37-57 d of age, these findings cannot rule out the possibility that some segregation would eventually have occurred even if the blockade had been continued. Thus, binocular impulse blockade may only delay the formation of ocular dominance columns by several weeks rather than prevent it entirely. Longer-term blockades will be required to settle this issue.

A number of control experiments indicate that the blockade of impulse discharge, rather than some side effect of the experimental procedures, accounts for these findings. First, neither the eye injections themselves nor the vehicle solution in which the TTX was suspended interfered with binocular segregation in the cortex. Neither did the presence of TTX in the systemic circulation. Finally, deprivation of vision itself by lid suture or dark-rearing also allowed a considerable degree of binocular segregation.

The present experiments cannot, however, entirely exclude the possibility that some effect of TTX on the eye other than its blockade of discharge activity may contribute to the effects noted here. A subtle impairment of axonal transport, for example, would not have been detected by the transneuronal labeling method employed in this study. This possibility has been addressed only by more recent experiments (Stryker and Strickland, 1984).

A comparison of the results from TTX-treated animals with those from the other binocularly deprived animals suggests that the spontaneous discharge of retinal ganglion cells is important for the normal developmental reorganization of binocular connections in the visual cortex. The blockade of spontaneous activity is the major difference apparent between the rearing his- 

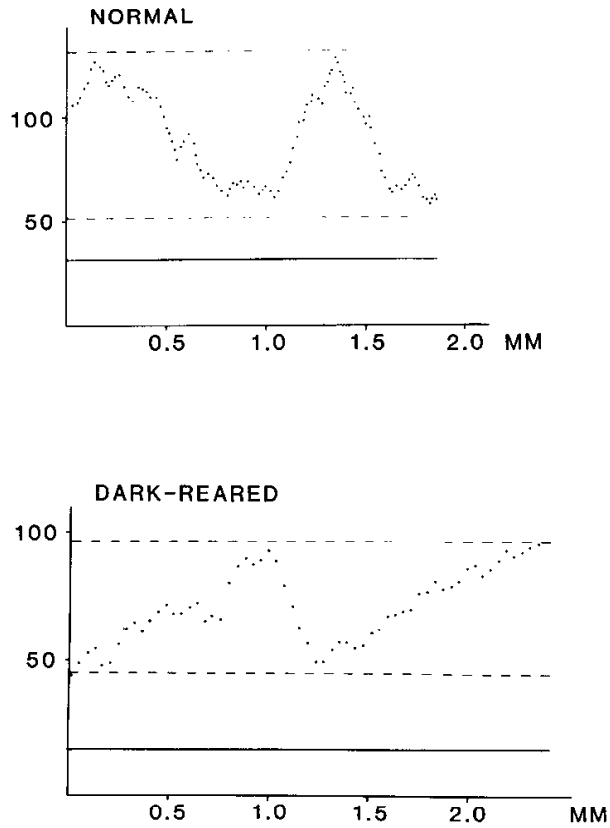
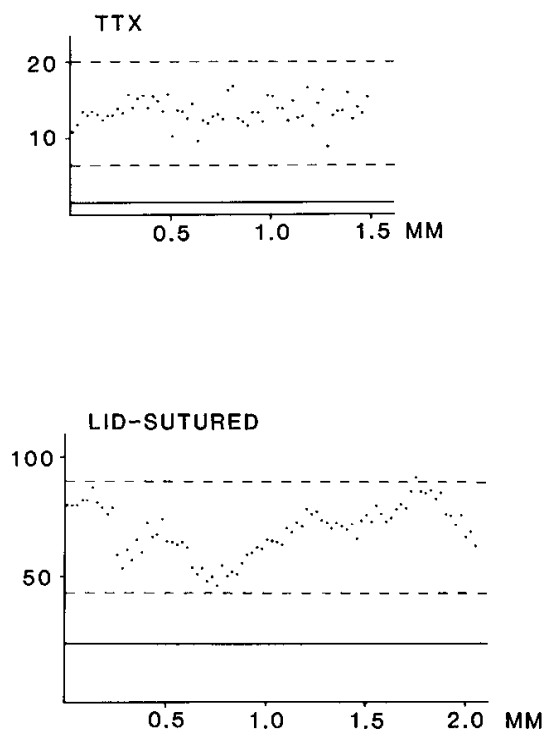

Figure 18. Grain counts from layer IVc of the visual cortex ipsilateral to the injected eye in a normal cat perfused at $39 \mathrm{~d}$ of age (data from LeVay et al., 1978), cat 37 from the experimental group (TTX), cat 17 from the dark-reared group, and cat 44 from the lid-sutured group. Ordinates plot distance along the base of layer IV (in $\mathrm{mm}$ ); abscissas plot grain density per $1000 \mu \mathrm{m}^{2}$. Background grain density indicated by solid horizontal line. Theoretical maximum and minimum grain densities calculated from geniculate spillover measurements (see text) indicated by dashed lines. Note that fluctuations in cortical grain densities approach theoretical maxima and minima in all except the experimental group. tory of the TTX-treated animals and those in the other deprived groups.

This finding does not, however, shed light on the nature of the role of spontaneous retinal activity in the organization of central connections. One clear possibility is that this role is instructional, in that the correlation of discharge among neighboring ganglion cells may inform the geniculocortical afferent terminals with which other terminals they should cluster. Indeed, the results of visual deprivation, especially alternating monocular occlusion and experimental strabismus (Hubel and Wiesel, 1965; Van Sluyters and Levitt, 1980), support such a mechanism. Alternatively, the role of spontaneous activity in these young animals may be merely permissive. Further experiments in progress, in which the timing of retinal ganglion cell discharge is brought under experimental control, are necessary to clarify this (Stryker and Strickland, 1984).

\section{Afferent segregation in other visual systems}

Work on other systems in which segregation of afferent terminals occurs lcads to similar conclusions about the role of electrical activity. In frogs and fish, ocular dominance "patches" can be induced in the tectum by various manipulations that cause 2 separate retinal projections to occupy a single tectal region (Constantine-Paton and Law, 1978; Fawcett and Willshaw, 1982; Ide et al., 1983; Levine and Jacobson, 1975; Schmidt, 1978). Blocking retinal activity with TTX during the time at which columns form blocks the segregation of retinal terminals (Boss and Schmidt, 1984; Constantine-Paton and Reh, 1983; Meyer, 1982). Recent work on the developing hamster visual system (Thompson and Holt, unpublished observations) is also consistent with these results. The rostral portion of the normal adult hamster's superior colliculus receives a segregated input from the 2 eyes. This segregation occurs during early postnatal development and can be blocked by binocular injections of TTX. Thus, the role of activity in arranging otherwise identical inputs to a particular structure may be important in the CNS of all vertebrates. That laminar segregation and gross topography appear normal in all these systems (see also Harris, 1980, 1981, 1984) indicates that the role of activity is a subtle one, important in the refinement of connections (Meyer, 1983; Schmidt and Edwards, 1983).

\section{Development of the retinogeniculate projection and the effects of activity blockade}

Retinal projections from the 2 eyes initially occupy overlapping territories in the lateral geniculate nucleus of monkey (Rakic, 1976) and cat (Shatz, 1983) during prenatal life. In the cat, Shatz and Kirkwood (1984) have shown that many individual geniculate neurons are functionally connected to both eyes during the time at which the 2 projections overlap.

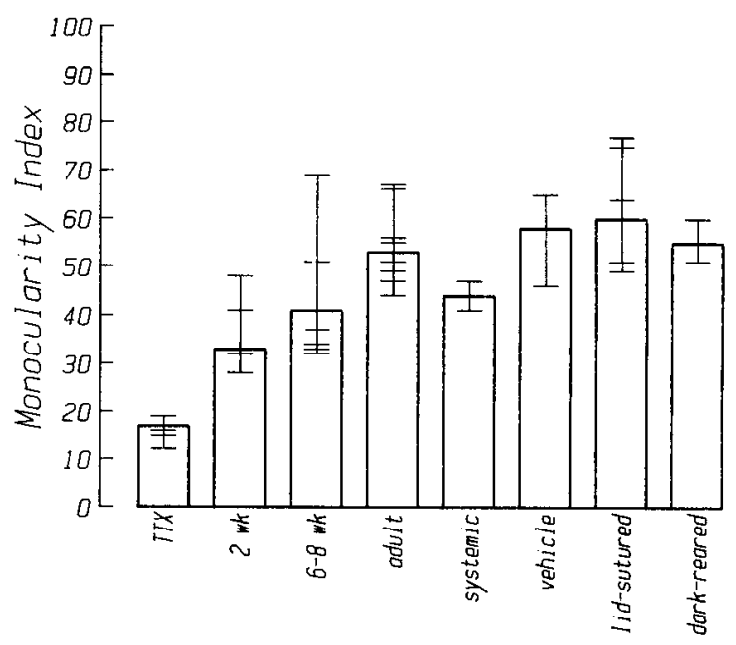

Figure 19. Monocularity indices calculated as described in text from physiological data for all animals studied. Histogram bars represent the values of this index for the pooled data from each group. Data from each individual animal indicated by short horizontal line. Vertical lines are error bars that display the range of individual animal data in each group. Names of groups as in Figures 10 and 18, plus systemic for the animals receiving systemic infusions of TTX and vehicle for the animals receiving intravitreal injections of the citrate buffer solution. Note that data from experimental (TTX) group is out of the range of variation found in normal animals, while data from all control groups overlap with normal data. 
During fetal life, this projection is rearranged (Rakic, 1976; Shatz, 1983). By adulthood, nearly all retinogeniculate terminations are made in exclusive eye-specific laminae (Bowling and Michael, 1980; Sur and Sherman, 1982). Although Kirkwood and Shatz (1983) have shown the capacity of this system for functional synaptic transmission, it is not known whether the rearrangement that occurs in fetal life depends on electrical activity. However, for the first 2 weeks after birth (after the rearrangement appears to be nearly complete), blockade of electrical activity in 1 eye can disrupt the functional segregation of the 2 eyes' terminals to a limited extent, so that an abnormally high proportion of geniculate neurons either remain or come to be binocularly activated (Archer et al., 1982; Dubin et al., 1986).

In addition to the functional and gross anatomical segregation of the 2 eyes' terminals, at least 3 other types of functional segregation are evident in the retinal connections to geniculate neurons. On- and Off-center ganglion cells connect specifically to different geniculate neurons, with very little overlap (Cleland et al., 1971b). X and Y ganglion cells also connect preferentially to different geniculate neurons (Cleland et al., 1971a; Hoffmann et al., 1972). Finally, geniculate neurons receive input from multiple retinal ganglion cells only when those cells are nearneighbors, giving rise to compact geniculate receptive fields (Cleland et al., 1971b). All these types of functional specificity were also disrupted by retinal blockade during the first 2 postnatal weeks (Archer et al., 1982). However, the topographic organization was grossly normal (Archer et al., 1982) - as in the fish and amphibian studies discussed above.

The geniculate effects of monocular retinal blockade were present in only a very attenuated form when blockade was begun at 11-15 d of age (Archer et al., 1982) and were absent when blockade was begun later than 15-20 d of age (Dubin and Stark, 1983). One would therefore expect that such geniculate abnormalities did not occur in the present experiment. Consistent with this expectation, our geniculate recordings, although not sufficiently quantitative to reveal subtle abnormalities, did reveal a segregation of monocular responses as the microelectrode passed from lamina $\mathrm{A}$ to $\mathrm{Al}$ to $\mathrm{C}$ that was as clear as in normal cats. It seems extremely unlikely, then, that the enhanced cortical binocularity observed after retinal blockade in the present study was due to binocular responses of geniculate cells.

\section{Earlier studies of ocular dominance columns}

It is worthwhile to consider the evidence in the literature for ocular dominance columns and the arrangement of geniculocortical afferents into stripes or patches in the visual cortex of the normal cat and monkey. Such a consideration should both allow us to assess the present evidence and indicate what additional evidence one might hope to obtain about the state of these afferents in the various developing and deprived animals of the present study.

\section{Evidence for normal adult organization}

The carly cvidence for a grouping of cells according to ocular dominance was from microelectrode studies (Hubel and Wiesel, 1962). This grouping was most apparent in recordings made from kittens subjected to artificial strabismus or alternating monocular occlusion, though evidence was still lacking at that point that "the walls separating [the two eyes' ocular dominance columns were] perpendicular to the cortical layers" (Hubel and Wiesel, 1965). The segregation of geniculocortical afferents serving the 2 eyes was suggested as a possible anatomical substrate for such ocular dominance groupings in 1965 (Hubel and Wiesel) and was later confirmed for the monkey by making lesions in single geniculate laminae and staining the cortex for degenerating terminals using a modified Nauta method (Hubel and Wiesel, 1969, 1972). Transneuronal transport of tritiated amino acids and sugars injected into 1 eye was later used to demonstrate the overall arrangement of geniculocortical afferents in monkey (Wiesel et al., 1974) and cat (Shatz et al., 1977). Transneuronal transport of wheat germ agglutinin conjugated to horseradish peroxidase (WGA-HRP) revealed a similar pattern of labeling (Anderson et al., 1983; Itaya and Van Hoesen, 1982).

Differences in cortical metabolic activity produced by visual stimulation of 1 eye while the other eye was closed or enucleated were detected using the 2-deoxyglucose (Kennedy et al., 1976) and cytochrome oxidase (Hendrickson et al., 1981; Horton and Hubel, 1981; Wong-Riley, 1979; Wong-Riley and Riley, 1983) methods. In monkey, but not in cat, the ocular dominance array in layer IV was also made visible in normal material stained by a modified Liesegang method (LeVay et al., 1975). Finally, in the cat, but not yet in the monkey, the terminal arbors of single geniculocortical afferent fibers were reconstructed in their entirety following either bulk deposits of HRP into the optic radiations (Ferster and LeVay, 1978) or intracellular filling of single, physiologically identified fibers within the cortex or immediate subcortical white matter (Gilbert and Wiesel, 1979; Humphrey et al., 1984).

\section{Evidence for abnormal organization of ocular dominance columns following early monocular deprivation}

Physiological recordings in kittens that had been deprived of vision in 1 eye revealed a dramatic and largely irreversible loss in the effectiveness of the deprived eye (Wiesel and Hubel, 1963, 1965b), accompanied by a shrinkage in the deprived LGN cells, that was not apparent when both eyes were deprived (Wiesel and Hubel, 1965a). The susceptibility to these effects of monocular deprivation was greatest during a critical period in early life (Hubel and Wiesel, 1970). This physiological change was greatest in the upper and lower cortical layers; in layer IV it matched precisely the reduction in the territory of the geniculocortical projection serving the deprived eye, as demonstrated by Nauta and Liesegang methods in the monkey and by transneuronal autoradiography in monkey and cat (Hubel et al., 1977; LeVay et al., 1980; Shatz and Stryker, 1978). In the monkey, the deoxyglucose method also revealed the abnormal but columnar pattern of ocular dominance following monocular deprivation (Des Rosiers et al., 1978). Cytochrome oxidase staining revealed a complex series of changes (Wong-Riley, 1979).

\section{Evidence for development of ocular dominance columns by progressive segregation}

Transneuronal autoradiographic labeling demonstrated that ocular dominance patches appeared, at least in rudimentary form, 3 weeks prenatally in the monkey (Rakic, 1976). On or near the day of birth, physiological recording and deoxyglucose methods revcalcd considcrable segregation of the 2 eyes' influences, not only on layer IV, but on the upper and lower layers as well, although many more binocularly driven cells were found in layer IV at this age than later (Des Rosiers et al., 1978; Hubel et al., 1977; LeVay et al., 1980). The periodic labeling of layer IV following an injection of tritiated amino acid into 1 eye changed from a gentle fluctuation into clear patches over the first 3-6 weeks of life (Hubel et al., 1977; LeVay et al., 1980).

In the cat, physiological recording and transneuronal labeling both indicated complete binocular overlap in the visual cortex before 2.5 weeks of age (LeVay et al., 1978). Quantitative transneuronal autoradiography suggested that segregation is progressive (LeVay et al., 1978), and the physiological findings of the present paper are consistent with this notion. Some presumed geniculocortical afferents reconstructed from Golgi material prior to 2 weeks of age had continuous terminal arbors that spanned widths equivalent to 2-3 adult ocular dominance patches (LeVay and Stryker, 1979); gaps were always evident in the arbors of such large afferents in adult material (Ferster and LeVay, 1978). Evidence about individual geniculocortical 
terminal arbors at the presumed intermediate stages of the segregation process is unfortunately lacking so far, as are quantitative deoxyglucose, cytochrome oxidase, and transneuronal WGA-HRP studies.

\section{Evidence for at least partial segregation of ocular dominance columns under conditions of binocular deprivation}

The prenatal partial segregation of ocular dominance columns in the monkey, reviewed in the previous section, takes place essentially in darkness and certainly in the absence of pattern vision. Dark-rearing from the age of $3 \mathrm{~d}$ did not prevent the completion of the segregation process in the monkey as judged from transneuronal autoradiographic labeling (LeVay et al., 1980). Indeed, abnormally little binocular interaction was found in month-old animals that had been lid-sutured near the time of birth (Hubel and Wiesel, 1974).

In the cat, both electrophysiological (see Sherman and Spear, 1982) and transneuronal autoradiographic labeling techniques have been applied to the question of whether ocular dominance segregation occurs when animals are deprived of pattern vision by either dark-rearing or bilateral lid suture. In most studies of lid-sutured animals, the proportion of binocularly driven cells is somewhat lower than normal (Blakemore and Van Sluyters, 1975; Kratz and Spear, 1976; Sherk and Stryker, 1976; Watkins et al., 1978; Wiesel and Hubel, 1965), in accord with the findings of the present report. Studies of dark-reared animals report reduced (Cynader et al., 1976; Leventhal and Hirsch, 1980) or normal (Buisseret and Imbert, 1976; Fregnac and Imbert, 1978) proportions of binocularly driven cells, also in accord with the present report. In a study attempting to map multiunit responses of geniculate afferent fibers in layer IV of area 17 in dark-reared cats, Swindale and Cynader (1983) found that there were many regions in which responses could be obtained only from one eye or the other, implying that at least a functional segregation of the afferents had taken place. Such physiological findings suggest that neither form of deprivation prevents the segregation of effective cortical inputs by eye.

Transneuronal labeling studies in visually inexperienced cats appear to be more controversial. At one extreme is the report of Swindale (1981) entitled "Absence of ocular dominance patches in dark-reared cats"; while the present findings appear to lie at the other extreme, in that some of the most distinct fluctuations in the transneuronal labeling of layer IV in both dark-reared and lid-sutured animals approach the theoretical limits set by spillover in the lateral geniculate nucleus (LeVay et al., 1978). The autoradiographs from the dark-reared animal in the Swindale (1981) report, however, show clearly periodic fluctuations in the transneuronal labeling of layer IV, although these fluctuations are much less pronounced than those illustrated in the normal cat. A study by Kalil (1982) reported that peak-to-trough fluctuations in the labeling of layer IV were 2.0 in dark-reared and lid-sutured cats, 2.9 in normal cats, and as high as 4.8 in strabismic cats. The measurements of the most recent study (Mower et al., 1985) yield Michaelson contrast ratios in the transneuronal labeling of 0.3 and 0.35 for darkreared and lid-sutured cats, respectively (equal to 1.9 and 2.1 when expressed as peak-to-trough ratios in the same form as Kalil's), in comparison to an average of 0.75 for normal cats. Thus, all reports are in agreement that considerable anatomical segregation of afferents takes place-perhaps as much as takes place in the monkey in utero-even under conditions of complete visual deprivation by dark-rearing. None of the findings on visually deprived cats are similar to those of the TTX cats of the present study.

A remaining area of uncertainty is to what to attribute the generally less-pronounced fluctuations in transneuronal labeling seen in the visually deprived as compared to normal animals. Some part of the smaller degree of fluctuation in the cortical labeling is likely to be duc to the $50 \%$ greater geniculate spillover in the dark-reared than in the other normal and deprived cats of the present study. (None of the other studies of deprived animals measured spillover into postsynaptic cells of the LGN.) But this seems unlikely to account for the entire difference between the dark-reared and normal animals, and it does not account for the generally less pronounced fluctuations present in lid-sutured animals, in which spillover was found to be similar to that in normal animals of the same age. It will be important to apply other transneuronal labeling methods that may differ in the extent of the "spillover" artifact to dark-reared and lid-sutured animals (Anderson et al., 1983).

One hypothesis to account for the difference between the labeling patterns in normal and deprived animals, along lines suggested by Swindale and Cynader (1983), is that under conditions of visual deprivation, geniculocortical afferents may segregate the most profuse and functionally most effective portions of their arbors but may not completely lose fine, relatively ineffective, and relatively poorly labeled branches. To verify this hypothesis will require the examination of substantial numbers of single geniculocortical afferent arbors, reconstructed following either bulk or intracellular fills (Ferster and LeVay, 1978; Gilbert and Wiesel, 1979).

\section{Evidence for failure of ocular dominance segregation under conditions of bilateral retinal blockade}

The present study used physiological recording and transneuronal autoradiographic labeling to demonstrate the failure of ocular dominance segregation under conditions of bilateral retinal blockade. Neither of these methods is free from possible artifact. The binocular responses obtained from the microelectrode studies could result from a profusion of intrageniculate or corticocortical binocular connections, for example, rather than a failure of geniculocortical afferent segregation. Our geniculate physiology, though not quantitative, shows that geniculate cells remain at least predominantly monocularly driven, but a subtle alteration at that level or even a gross alteration in corticocortical connections, however unlikely, might not have been detected. Similarly, the lack of fluctuation in cortical transneuronal labeling could result from a spillover artifact at the geniculate or cortical level that is not properly accounted for by our geniculate measurements. It will be important to confirm the conclusions of this study using other transneuronal labeling methods (Anderson et al., 1983), single-axon reconstructions (Ferster and LeVay, 1978; Gilbert and Wiesel, 1979), and metabolic labeling techniques for demonstrating overall patterns of binocular responsiveness (Des Rosiers et al., 1978).

\section{References}

Anderson, P. A., J. Olavarria, and R. C. Van Sluyters (1983) The pattern of ocular dominance columns in areas 17 and 18 of normal and visually deprived cats as revealed in tangential sections of the unfolded cortex. Soc. Neurosci. Abstr. 9: 910.

Archer, S. M., W. M. Dubin, and L. A. Stark (1982) Abnormal retinogeniculate connectivity in the absence of action potentials. Science 217: 743-745.

Blakemore, L., and R. Van Sluyters (1975) Innate and environmental factors in the development of the kitten's visual cortex. J. Physiol. (Lond.) 248: 663-716.

Boss, V. C., and J. T. Schmidt (1984) Activity and the formation of ocular dominance patches in dually innervated tectum of goldfish. $\mathrm{J}$. Neurosci. 4: 2891-2905.

Bowling, D. B., and C. R. Michael (1980) Projection patterns of single physiologically characterized optic tract fibers in cat. Nature 286 . 899-902.

Buisseret, P., and P. Imbert (1976) Visual cortical cells: Their developmental properties in normal and dark-reared kittens. J. Physiol (Lond.) 255: 511-525.

Cleland, B. G., W. M. Dubin, and W. R. Levick (1971a) Sustained 
and transient neurones in the cat's retina and lateral geniculate nucleus. J. Physiol. (Lond.) 217: 473-496.

Cleland, B. G., W. M. Dubin, and W. R. Levick (1971b) Simultaneous recording of input and output of lateral geniculate neurones. Nature [New Biol.] 231: 191-192.

Constantine-Paton, M., and M. I. Law (1978) Eye-specific termination bands in tecta of three-eyed frogs. Science 202: 639-641.

Constantine-Paton, M., and T. Reh (1983) Eye-specific stripes in the tectal lobes of three-eyed frogs are dependent on neural activity. Soc. Neurosci. Abstr. 9: 760.

Cynader, M., N. Berman and A. Hein (1976) Recovery of function in cat visual cortex following prolonged deprivation. Exp. Brain Res. 25: $139-156$.

Des Rosiers, M. H., O. Sakurada, J. Jehle, M. Shinohara, C. Kennedy, and L. Sokoluff (1978) Demonstration of functional plasticity in the immature striate cortex of the monkey by means of the $\left[{ }^{14} \mathrm{C}\right]$ deoxyglucose method. Science 200: 447-449.

Dubin, M., and L. Stark (1983) Time-course of effects of action potential blockade on development of retino-geniculate connections in kittens. Invest. Ophthalmol. Suppl. 24: 138.

Dubin, M. W., L. A. Stark, and S. M. Archer (1986) A role for actionpotential activity in the development of neuronal connections in the kitten retinogeniculate pathway. J. Neurosci. 6: 1021-1036.

Fawcett, J. W., and D. J. Willshaw (1982) Compound eyes project stripes on the optic tectum in Xenopus. Nature 296: 350-352.

Ferster, D., and S. LeVay (1978) The axonal arborizations of lateral geniculate neurons in the striate cortex of the cat. J. Comp. Neurol. 182: 923-944.

Fregnac, Y., and M. Imbert (1978) Early development of visual cortical cells in normal and dark-reared kittens: Relationship between orientation selectivity and ocular dominance. J. Physiol. (Lond.) 278: 27-44.

Gilbert, C. D. (1983) Microcircuitry of the visual cortex. In Annual Review of Neuroscience, W. M. Cowan, E. M. Shooter, C. F. Stevens, and R. F. Thompson, eds., pp. 217-248, Annual Reviews Inc., Palo Alto, CA.

Gilbert, C. D., and T. N. Wiesel (1979) Morphology and intracortical projections of functionally characterised neurones in the cat visual cortex. Nature 280: 120-125.

Harris, W. A. (1980) The effects of eliminating impulse activity on the development of the retinotectal projection in salamanders. J. Comp. Neurol. 194: 303-317.

Harris, W. A. (1981) Neural activity and development. Annu. Rev. Physiol. 43: 689-710.

Harris, W. A. (1984) Axonal pathfinding in the absence of normal pathways and impulse activity. J. Neurosci. 4: 1153-1162.

Hendrickson, A. E., S. P. Hunt, and J.-Y. Wu (1981) Immunocytochemical localization of glutamic acid decarboxylase in monkey striate cortex. Nature 292: 605-607.

Hoffmann, K.-P., J. Stone, and S. M. Sherman (1972) Relay of receptive-field properties in dorsal lateral geniculate nucleus of the cat. J. Neurophysiol. 35: 518-531.

Horton, J. C., and D. H. Hubel (1981) Regular patchy distribution of cytochrome oxidase staining in primary visual cortex of macaque monkey. Nature 292: 762-764.

Hubel, D. H., and T. N. Wiesel (1962) Receptive fields, binocular interaction and functional architecture in the cat's cortex. J. Physiol. (Lond.) 160: 106-154.

Hubel, D. H., and T. N. Wiesel (1963) Receptive fields of cells in striate cortex of very young, visually inexperienced kittens. J. Neurophysiol. 26: 994-1002.

Hubel, D. H., and T. N. Wiesel (1965) Binocular interaction in striate cortex of kittens reared with artificial squint. J. Neurophysiol. 28: 1041-1059.

Hubel, D. H., and T. N. Wiesel (1969) Anatomical demonstration of columns in the monkey striate cortex. Nature 221: 747-750.

Hubel, D. H., and T. N. Wiesel (1970) The period of susceptibility to the physiological effects of unilateral eye closure in kittens. J. Physiol. (Lond.) 206: 419-436.

Hubel, D. H.. and T. N. Wiesel (1972) Laminar and columnar distribution of geniculocortical fibers in the macaque monkey. J. Comp. Neurol. 146: 421-450.

Hubel, D. H., and T. N. Wiesel (1977) Functional architecture of macaque monkey visual cortex. Proc. R. Soc. London [Biol.] 198: 159.
Hubel, D. H., T. N. Wiesel, and S. LeVay (1977) Plasticity of ocular dominance columns in monkey striate cortex. Phil. Trans. R. Soc. London [Biol.] 278: 377-409.

Humphrey, A. L., M. Sur, D. J. Uhlrich, and S. M. Sherman (1984) Projection patterns of individual X-and Y-cell axons from the lateral geniculate nucleus to cortical area 17 in the cat. J. Comp. Neurol. 233: $159-189$

Ide, C. R., S. E. Fraser, and R. L. Meyer (1983) Eye dominance columns formed by an isogenic double nasal frog eye. Science 221 : 293-295.

Itaya, S. K., and G. W. Van Hoesen (1982) WGA-HRP as a transneuronal marker in the visual pathways of monkey and rat. Brain Res. 236: 199-204.

Kalil, R. E. (1982) Development of ocular dominance columns in cats reared with binocular deprivation or strabismus. Soc. Neurosci. Abstr. 8: 4.

Kennedy, C., M. Des Rosiers, O. Sakurada, M. Shinohara, M. Reivich, J. Jehle, and L. Sokoloff (1976) Metabolic mapping of the primary visual system of the monkey by means of the autoradiographic $\left[{ }^{14} \mathrm{C}\right]$ deoxyglucose technique. Proc. Natl. Acad. Sci. USA 73: 4230-4234.

Kirkwood, P. A., and C. J. Shatz (1983) Development of binocular inputs to dorsal lateral geniculate neurones in the fetal cat. J. Physiol. (Lond.) 336: 27P-28P.

Kratz, K. E., and P. D. Spear (1976) Effects of visual deprivation and alterations in binocular competition on responses of striate cortex neurons in the cat. J. Comp. Neurol. 170: 141-152.

LeVay, S., and M. P. Stryker (1979) The development of ocular dominance columns in the cat. In Aspects of Developmental Neurobiology (Soc. Neurosci. Symp.), J. A. Ferrendelli, ed., pp. 83-98, Society for Neuroscience, Bethesda.

LeVay, S., D. H. Hubel, and T. N. Wiesel (1975) The pattern of ocular dominance columns in macaque visual cortex revealed by a reduced silver stain. J. Comp. Neurol. 159: 559-576.

LeVay, S., M. P. Stryker, and C. J. Shatz (1978) Ocular dominance columns and their development in layer IV of the cat's visual cortex: A quantitative study. J. Comp. Neurol. 179: 223-224.

LeVay, S., T. N. Wiesel, and D. H. Hubel (1980) The development of ocular dominance columns in normal and visually deprived monkeys. J. Comp. Neurol. 191: 1-51.

Leventhal, A. G., and H. V. B. Hirsch (1980) Receptive-field properties of different classes of neurons in visual cortex of normal and dark-reared cats. J. Neurophysiol. 43: 1111-1132.

Levine, R., and M. Jacobson (1975) Discontinuous mapping of retina into tectum innervated by both eyes. Brain Res. 98: 172-176.

Mastronarde, D. N. (1983a) Correlated firing of cat retinal ganglion cells. I. Spontaneously active inputs to $X$ - and $Y$-cells. J. Neurophysiol. 49: 303-324.

Mastronarde, D. N. (1983b) Correlated firing of cat retinal ganglion cells. II. Responses of $\mathrm{X}$ - and $\mathrm{Y}$-cells to single quantal events. J. Neurophysiol. 49: 325-349.

Meyer, R. L. (1982) Tetrodotoxin blocks the formation of ocular dominance columns in goldfish. Science 218: 589-591.

Meyer, R. L. (1983) Tetrodotoxin inhibits the formation of refined retinotopography in goldfish. Dev. Brain Res. 6: 293-298.

Mower, G. D., C. J. Caplan, W. G. Christen, and F. H. Duffy (1985) Dark-rearing prolongs physiological but not anatomical plasticity of the cat visual cortex. J. Comp. Neurol. 235: 448-466.

Rakic, P. (1976) Prenatal genesis of connections subserving ocular dominance in the rhesus monkey. Nature 261: 467-471.

Rakic, P. (1977) Prenatal development of the visual system in rhesus monkey. Phil. Trans. R. Soc. London [Biol.] 278: 245-260.

Schmidt, J. T. (1978) Retinal fibers alter tectal positional markers during expansion of the half-retinal projection in goldfish. J. Comp. Neurol. 177: 279-300.

Schmidt, J. T., and D. L. Edwards (1983) Activity sharpens the map during the regeneration of the retinotectal projection in goldfish. Brain Res. 269: 29-39.

Shatz, C. J. (1983) The prenatal development of the cat's retinogeniculate pathway. J. Neurosci. 3: 482-499.

Shatz, C. J., and P. A. Kirkwood (1984) Prenatal development of functional conncctions in the cat's retinogeniculate pathway. J. Neurosci. 4: 1378-1397.

Shatz, C. J., and M. P. Stryker (1978) Ocular dominance in layer IV of the cat's visual cortex and the effects of monocular deprivation. J. Physiol. (Lond.) 281: 267-283. 
Shatz, C. J., S. H. Lindstrom, and T. N. Wiesel (1977) The distribution of afferents representing the right and left eyes in the cat's visual cortex. Brain Res. 131: 103-116.

Sherk, H., and M. P. Stryker (1976) Quantitative study of cortical orientation selectivity in visually inexperienced kittens. J. Neurophysiol. 39: 63-70.

Sherman, S. M., and P. D. Spear (1982) Organization of visual pathways in normal and visually deprived cats. Physiol. Rev. 62: 738855.

Sokoloff, L., M. Reivich, C. Kennedy, M. H. Des Rosiers, C. S. Patlak, K. D. Pettigrew, O. Sakurada, and M. Shinohara (1977) The ${ }^{14} \mathrm{C}$ deoxyglucose method for the measurement of local cerebral glucose utilization: Theory, procedure, and normal values in the conscious and anesthetized albino rat. J. Neurochem. 28: 897.

Stryker, M. P. (1980) Synapse elimination in the developing visual system. Soc. Neurosci. Abstr. 6: 29.

Stryker, M. P. (1981) Late segregation of geniculate afferents to the cat's visual cortex after recovery from binocular impulse blockade. Soc. Neurosci. Abstr. 7: 842.

Stryker, M. P. (1982) Role of visual afferent activity in the development of ocular dominance columns. Neurosci. Res. Prog. Bull. 20: 540-549.

Stryker, M. P., and S. L. Strickland (1984) Physiological segregation of ocular dominance columns depends on the pattern of afferent electrical activity. Invest. Ophthalmol. Suppl. 25: 278.

Sur, M., and S. M. Sherman (1982) Retinogeniculate terminations in cats: Morphological differences between $\mathrm{X}$ and $\mathrm{Y}$ cell axons. Science 218: 389-391.

Swindale, N. V. (1981) Absence of ocular dominance patches in darkreared cats. Nature 290: 332-333.

Swindale, N. V., and M. S. Cynader (1983) Physiological segregation of geniculate afferents in the visual cortex of dark-reared cats. Soc. Neurosci. Abstr. 9: 24.

Van Sluyters, R. C., and F. B. Levitt (1980) Experimental strabismus in the kitten. J. Neurophysiol. 43: 686-699.

Watkins, D. W., J. R. Wilson, and S. M. Sherman (1978) Receptivefield properties of neurons in binocular and monocular segments of striate cortex in cats raised with binocular lid suture. J. Neurophysiol. 41: 322-337.

Wiesel, T. N., and D. H. Hubel (1963) Single-cell responses in striate cortex of kittens deprived of vision in one eye. J. Neurophysiol. 26: 1003-1017.

Wiesel, T. N., and D. H. Hubel (1965a) Comparison of the effects of unilateral and bilateral closure on cortical unit responses in kittens. J. Neurophysiol. 28: 1029-1040.

Wiesel, T. N., and D. H. Hubel (1965b) Extent of recovery from the effects of visual deprivation in kittens. J. Neurophysiol. 28: 10601072.

Wiesel, T. N., and D. H. Hubel (1974) Ordered arrangement of orientation columns in monkeys lacking visual experience. J. Comp. Neurol. 158: 307-318.

Wiesel, T. N., D. H. Hubel, and D. M. K. Lam (1974) Autoradiographic demonstration of ocular-dominance columns in the monkey striate cortex by means of transneural transport. Brain Res. 79: 273279.

Wong-Riley, M. T. T. (1979) Changes in the visual system of monocularly sutured or enucleated cats demonstrable with cytochrome oxidase histochemistry. Brain Res. 171: 11-28.

Wong-Riley, M. T. T., and D. A. Riley (1983) The effect of impulse blockage on cytochrome oxidase activity in the cat visual system. Brain Res. 261: 185-193. 